PRODUCT AND PRICE

COMPETITION IN A DUOPOLY

by

K. Sridhar Moorthy*

Working Paper Series No. MERC 83-10

August 1983

University of Rochester

Manageria1 Economics Research Center

Graduate School of Management

Rochester, New York 14627

*Financial support from the Managerial Economics Research Center is greatly appreciated. 


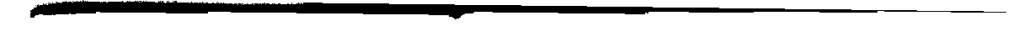

'

. 


\title{
PRODUCT AND PRICE COMPETITION IN A DUOPOLY
}

\author{
BY \\ K. SRIDHAR MOORTHY \\ University of Rochester
}

August 1983

\begin{abstract}
This paper provides a theoretical rationale for the dictum: It pays to find a niche in the market. Two (identical) firms compete on product (quality) and price, choosing products before prices. I identify conditions for the existence of a pure (perfect) Nash equilibrium. Different firms choose different products (and charge different prices) in equilibrium, but the equilibrium is inefficient: There is an alternative placement of two products that would increase total surplus.
\end{abstract}

This paper is based on my doctoral dissertation entitled Market Segmentation through Product Differentiation written at Stanford University, 1982. I Fish to thank my adviser Professor Robert B. Wilson for considersble help and encouragement. Any errors that remain are, of course, $m y$ own responsibility. Partial financisl support in the form of a summer research grant was provided by the Managerial Economics Research Center at The University of Rochester. 



\section{INTRODUCTION}

In this paper I study product and price competition in a duopoly. The intent is to substantiate rigorously the intuition behind the dictum: It pays to find a niche in the market. (Porter (1980) calls this a "focus strategy.") If firms have different strengths (and weaknesses)-for example, one firm has the technology to produce high-quality products, which the other firm lacksthen this proposition seems trivial; the "equilibrium" probably has each firm producing according to its strengths: a firm is limited in its choices to what it can do! But surely the intuition behind the original proposition is deeper than this. It has to with demand-side phenomena: if two firms have the same product, and consumers know this, then price will be the basis on which consumers choose between the two, whereas, if the products were different each firm could retain some monopoly power serving different segments. In other words, finding a niche in the market is supposed to be "optimal" even for identical firms.

My model has two identical firms and a continuum of consumer segments differentiated by their taste for a "quality-like" attribute-an attribute on which consumers agree in their preference orderings: Everyone prefers high quality to low quality, ceteris paribus. (Attributes like gas-mileage, performance, and durability are obvious examples.) I consider two cases of my model: one in which there is only one (lower) substitute, and the other in which there are substitutes at both ends. For the consumers, these substitutes represent alternative consumption opportunities; for the firms they represent additional competition, but competition whose products and prices can be taken as given. Each firm chooses a product (quality) first, simultaneously with the other firm, and then a price, also simultaneously with the other firm. A natural equilibrium concept in this set-up is that of a perfect pure Nash equilibrium: Given the product choices of the two firms, there exists a pure Nash equilibrium in prices and, anticipating these prices, the products are in (pure) Nash equilibrium too. 1 I identify conditions under which such an equilibrium exists. Aside from regularity conditions essentially guaranteeing existence of "local" best-responses for each firm, the key requirement turns out to be the

${ }^{1}$ This paper uses the methodology of noncooperative game theory hesvily; readers unfamiliar with this subject are urged to read Friedman (1977, pp. 15-68). 
following "boundary" condition: If from a product position where each firm is indifferent between going "up" or "down" one firm chooses to go up (down), then the best-response of the other firm should be to go down (up). When this boundary condition fails I show that there exists a mixed equilibrium involving identical randomizations by the two firms over two products. (This is interesting because the firms have available to them a continuum of products.) The pure equilibrium, however, is asymmetric: The firms choose distinct products (and charge distinct prices). In an example widely discussed in the literature I verify that there exists a pure equilibrium, in both the one-substitute and two-substitutes cases. In either case, the equilibrium is inefficient-there is an alternative placement of two products which would increase total surplus-but the two-substitutes equilibrium exhibits an interesting symmetry, not shared by the one-substitute case: The two (distinct) products are located at equal distances from the substitutes.

The paper is organized as follows. In the next section, I review the relevant literature-and there is a lot of it. In Section 3 I describe my model and note some of its basic properties. In Section 4 I define a perfect product-price equilibrium and present the main existence theorem. The next section begins the study of the example, with the one-substitute case. Section 6 considers the two-substitutes case. In Section 7 I make some general remarks about extending the main theorem to more than two firms. Section 8 concludes the paper. (All proofs are in Appendix 1. In addition, I have collected some basic fixed-point theorems-referred to in the sequel-in Appendix 2.)

\section{REVIEW OF THE LITERATURE}

Chamberlin's classic The Theory of Monopolistic Competition represents the first explicit recognition of the fact that much real-world competition involves product differentiation. Chamberlin recognized that an industry's competitiveness depends not only on the number of firms in it but also on the degree of substitutability among its products. However, his analysis takes the product locations as given. For an analysis with product as a strategic variable one must begin with Hotelling (1929). Hotelling's model also brings up an issue which pervades the product differentiation literature: the existence 
of a pure Nash equilibrium. ${ }^{2}$ Briefly, an equilibrium is a list of strategies, one for each firm in the oligopoly, such that no firm wants to unilaterally change its strategy.

In Hotelling's model two stores compete on location and price-for consumers distributed uniformly along a road. ${ }^{3}$ Hotelling seeks a perfect pure equilibrium in this framework: Given the firms' locations, the prices have to be in equilibrium, and anticipating these prices, the locations have to be in equilibrium too. His main result is the celebrated "Principle of Minimum Differentiation": in equilibrium the firms will locate back-to-back at the center of the market. 4 Unfortunately, the principle is invalid, as has been shown by Smithies (1941) and, more recently, by d'Aspremont, Gabssewicz, and Thisse (1979). The reason is that a pure price equilibrium fails to exist when the firms get close to each other: There cannot be an equilibrium with one firm out of the market-because the firm out of the market doesn't have to be out of the market: it can always charge the same price as its opponent; but when the firms are close to each other, undercutting becomes more lucrative than sharing the market. ${ }^{5}$

Two features of Hotelling's model are worth noting: (1) The consumers in the "hinterland" of each firm-the consumers on the side of the firm away from the other firm-are "captive" consumers for that firm as long as it has some market share from the consumers in between the two firms. This leads to a tendency to move toward the center from any "market-sharing equilibrium." (2) Relatively small changes in price lead to relatively large changes in market share when the firms are close to each other. This promotes rela-

${ }^{2}$ Henceforth, we ahall omit the appellation Nash" when referring to a Nash equilibrium.

${ }^{3}$ Of course, store location is just one example of an attribute on which consumers' idealpoints differ. The model applies oqually well to other interpretations: sweetness, sudsiness, etc.

${ }^{4}$ For applications of this principle to politics and advertising see Downs (1964) and Steiner (1961), respectively.

5 If firms compete on location alone, a pure equilibrium with the two firms located back-toback - at the medien of the consumer distribution, in general-oxists. This permits continued application of the Principle of Minimum Differentiation to politics and advertising. However, as Eaton and Lipsey (1975) have noted there is no such equilibrium with three firms. Also, a mixed equilibrium in products and prices exists in the Hotelling model; see Dasgupta and Maskin (1982b). 
tively "painless" undercutting-and nonexistence of a pure price equilibrium. Together, (1) and (2) lead inexorably to nonexistence of a perfect pure equilibrium; if either of these features were absent an equilibrium would be more likely to exist. d'Aspremont, Gabszewicz, and Thisse (1979) present an example with convex "transport costs" which eliminates (2); Novshek (1980) modifies the equilibrium concept by modifying the type of conjectures each firm makes about the other's strategy - his firms don't undercut because they believe that the other firm will not let itself be undersold at its own location. Economides (1980) presents a model in which consumers have "Bmall" reservation prices for the product being sold, so that consumers in the hinterland are not captive anymore. In all these cases, the equilibrium involves the firms taking up distinct locations!

Another stream of research has used "quality" type attributes. Here every consumer has the same ideal-point: the maximum feasible quality. Again, existence of an equilibrium is a problem. As noted by Novshek (1980) and Stokey (1980), there is no pure equilibrium with firms choosing quality and price simultaneously, at least with constant or increasing average costs. To see this, look at Figure 1. Suppose that it describes a situation where firm A's profits at an equilibrium are positive but not greater than that of firm $B$. (If $A$ makes zero profits, then surely it can find a distinct quality and/or a price above average cost that will yield positive profits.) Then, by choosing a quality $s_{A}^{\prime} \approx$ $s_{B}$ and pricing it just below $B$, firm A captures all of B's market and retains a fraction of its original market. The latter fraction is bounded away from zero (i.e. always positive), and thus yields a net increase in profits. Hence, the original situation can't be an equilibrium. With firms' products fixed, however, there generally exists a pure price equilibrium; see, for example, Gabszewicz and Thisse (1979). (With identical products, this is nothing but the wellknown Bertrand (1883) equilibrium.) This has led some authors to seek a twostage equilibrium in the spirit of Hotelling: Firms fix products first, and after observing all the product choices, determine their prices. Bresnahan (1981) and Shaked and Sutton (1982) (and the present paper-worked out independently of the other two) are examples of this approach. Bresnahan has firms choosing product lines, but is mainly interested in conditions that guarantee a mixed equilibrium. Shaked and Sutton have a model where marginal production 
Figure 1. Illustrating non-existence of a product-price equilibrium

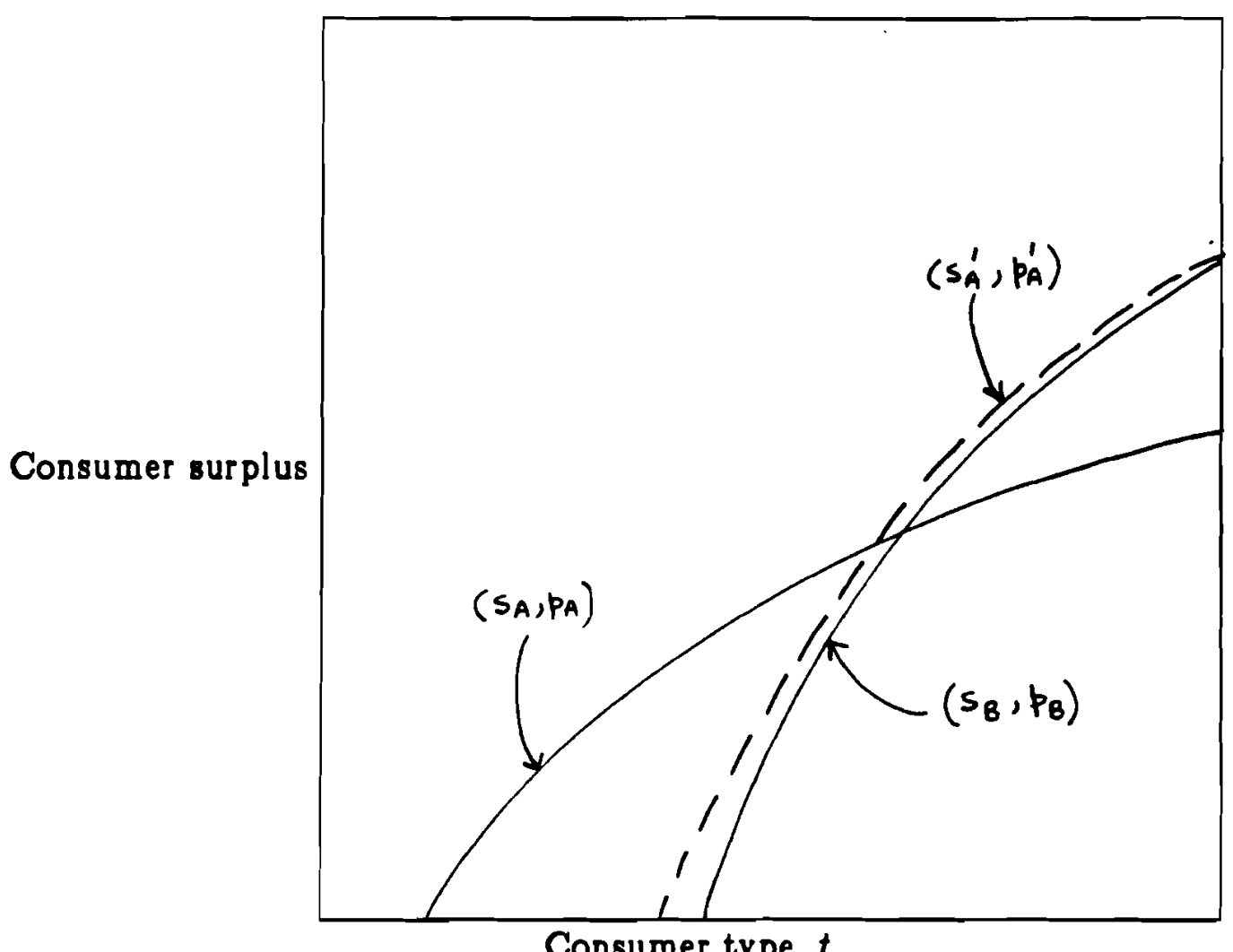

costs are independent of quality -80 that all consumers have the same favorite product with products priced at marginal cost-and show the existence of a pure perfect equilibrium in a duopoly. My model (described more fully in the next section) differs from Shaked and Sutton (1982) in having costs increasing with quality; a major consequence of this is that different consumers have different favorite products when the products are priced at marginal cost. In turn this enables an infinite number of products to make positive profits in price equilibrium; in the Shaked-Sutton model only a finite number can do so.

Entry in differentiated products industries is the subject of Hay (1976), Prescott and Visscher (1977), Gabszewicz and Thisse (1980), Lane (1980), Salop (1979), and Schmalansee (1978). In both Lane and Prescott and Visscher, firms enter in sequence, each firm chooses a single product after observing the choices of firms already in the market and (correctly) anticipating the locations of firms yet to enter, and prices are determined after all firms that can make a positive profit have entered. The major result is that firms that enter will 
optimally choose product locations to deter further entry; and these locations will, in general, be different from what they would have chosen if there were no threat of entry. Hay, Salop, and Schmalansee carry this idea gne step further by considering the possibility that firms may deter further entry by preempting all "available" product positions. Gabszewicz and Thisse have shown that if firms are myopic and there is only a finite number of qualities they can choose from, then the entry of each additional firm (at the highest quality level) beyond a certain number must provoke the exit of an incumbent (at the lowest quality level), but, nevertheless, profits of all firms fall. Hauser and Shugan (1983) focus on the "defensive" actions of an incumbent anticipating an entry, but theirs is not an equilibrium model: the incumbent does not take into account the reactions of the entrant.

\section{THE MODEL}

In the most general version of the model there are three product classes two of which are called substitutes-lower and upper-and the third is the product class from which the firms choose products to segment the market. We shall tentatively take the differentiated product class as $\Re_{+}=[0, \infty)$ and interpret it as representing the various levels of "quality" that can be chosen by the firms. Such an index always exists, even for multi-attribute products, as long as consumers agree in their preference ranking.

1 assume a one-dimensional continuum of consumer types (segments) indexed by $t \in \Re$ and distributed as $H(t)$ with support $[a, b], a<b$. I assume no income effects in the utility functions of these consumers so that their preferences can be parametrized by reservation prices-essentially I am assuming that each consumer's expenditure on the differentiated product class is a small fraction of her total expenditure. I further assume that each consumer buys just one unit of some product (i.e. inelastic demand) or one of the substitutes-these products are like durables. Let $u(t, \delta)$ denote the reservation price of a type-t consumer for a unit of product $s \in \Re_{+}$. The following properties of $u$ are crucial to the construction: 6

(3.1) For all $t \in(a, b], s \in(0, \infty), \quad u_{s}(t, s)>0, \quad u_{t}(t, s)>0, \quad u_{t s}(t, s)>0$.

${ }^{6}$ Hereafter, partial derivatives are denoted by subscripts (e.g., $u_{A}(t, s)=\frac{g_{u}}{\partial s}(t, s)$ ), and total derivatives by primes. 
Essentially, assumption (3.1) says that every consumer prefers a higher quality product to a lower quality product, and that a higher type, not only attaches greater value to a product than a lower type, but also has a greater intensity of preference for quality. One implication of this assumption is that reservation price functions of two distinct types cannot cross; another implication is that market segments are closed intervals (cf. Proposition 2 below).

There are 2 firms indexed $i=1,2$, each having the same constant (in quantity) marginal cost $c(s)$ for a unit of product $s \in \Re_{+}$. Note that there are no fixed costs dependent on $s$. (The lower and upper substitutes will be denoted by 0 and 3 , respectively.) I assume further that $c(\cdot)$ is strictly increasing and further that for all $t \in[a, b]$, there exists $s^{*}(t) \in[0, \infty)$ such that:

$$
\begin{array}{r}
u_{s}\left(t, s^{*}(t)\right)-d^{\prime}\left(s^{*}(t)\right)=0 \\
u_{s s}\left(t, s^{*}(t)\right)-c^{\prime \prime}\left(s^{*}(t)\right)<0 .
\end{array}
$$

I assume that each firm maximizes its profit knowing only the distribution of consumers of each type. I assume that each consumer maximizes surplus perceiving accurately the attributes of the product.

The model as specified above admits an immediate simplification by the simple device of redefining the type and quality indices.

PROPOSITION 1. Without loss of generality we can assume $[a, b]=[0,1], H(t)=$ $t, u(t, 0)=0$, and $c(0)=0$.

Note that Proposition 1 uses only the monotonicity of $u$ with respect to $t$ in allowing us to restrict attention to a uniform distribution without loss of generality; however, if one asumes additional structure on $u$, say $u(t, s)=t s$ (as I shall do in the example) or that $u$ is concave in $t$, then the uniform distribution becomes an essential restriction. Henceforth, I shall assume that $[a, b]=[0,1]$, $H(t)=t, u(t, 0)=0$, and $c(0)=0$. The force of the assumptions (3.1) is in giving a simple structure to the market for each product. Propositions 2 and 3 (stated generally, for $n$ products) summarize the basic properties. (See Figure 2.) 
Figure 2. Structure of Market Segments

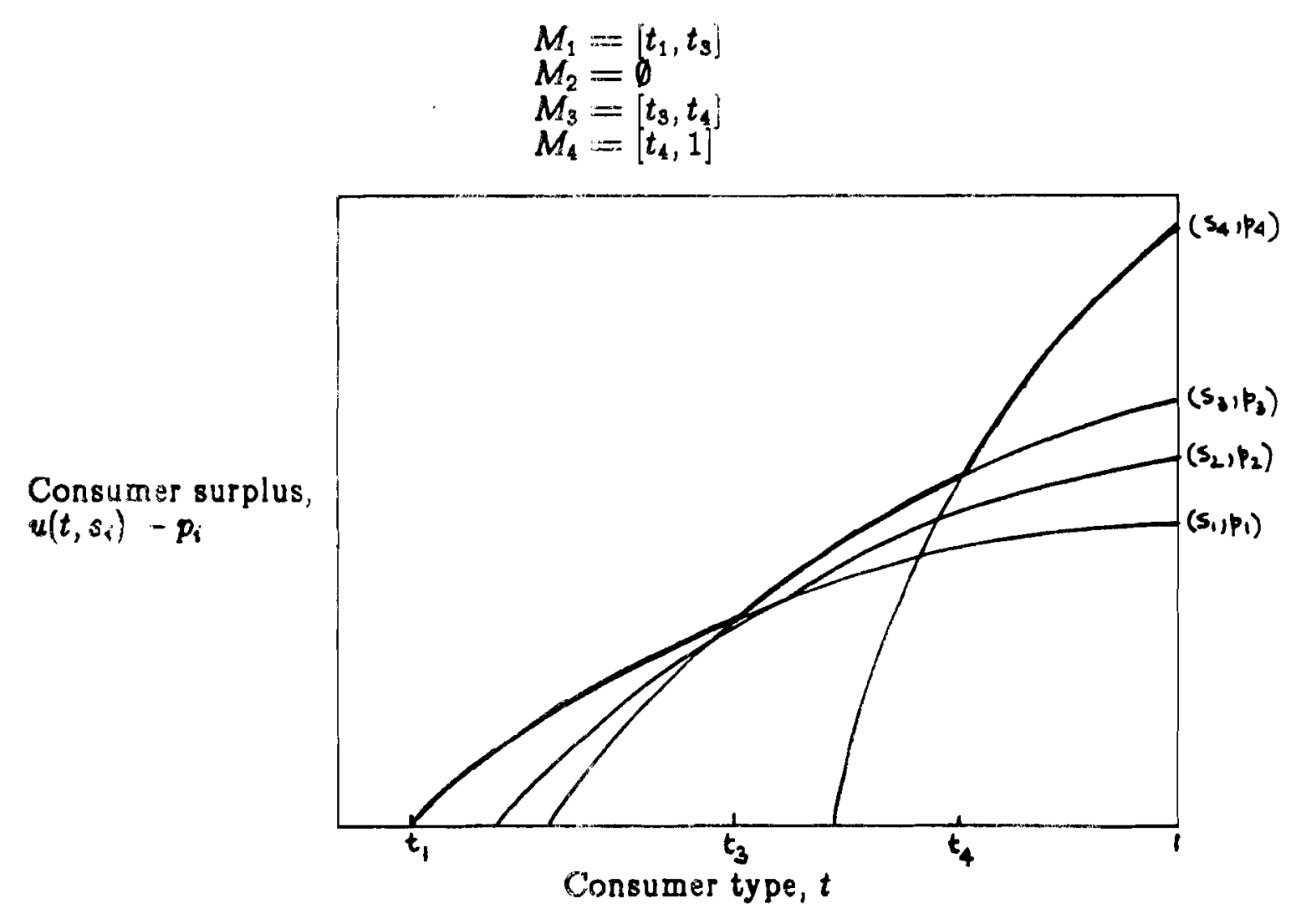


PROPOSITION 2. Let $0 \leq s_{1} \leq \cdots \leq s_{n}$ be $n$ products priced at $p_{1}, \ldots, p_{n}$, respectively. Then the market segment for $i(i=1, \ldots, n)$, defined as

$$
M_{i}=\left\{t \in[0,1]: u\left(t, s_{i}\right)-p_{i} \geq u\left(t, s_{j}\right)-p_{j} \text { for } j=0,1, \ldots, n+1\right\}
$$

can be characterized by:

1. $s_{i} \leq s_{j}$ and $p_{i}>p_{j} \Rightarrow M_{i}=\emptyset$,

2. $s_{i}<s_{j}, \quad t_{i} \in M_{i}, \quad t_{j} \in M_{j} \Rightarrow t_{i} \leq t_{j}$,

3. If $M_{i} \neq 0$, then $M_{i}=\left[t_{i}, t_{i+1}\right]$, where $t_{i}$ is either 0 or the type. of consumer indifferent between i and the next lower quality product with a nonempty market and similarly $t_{i+1}$ is either 1 or the type of consumer indifferent between $i$ and the next higher quality product with a nonempty market.

Another basic feature of the model is that $s^{*}(0)<s^{*}(1)$. This immediately implies that any finite number of firms can have a positive market share if their products fall in the interval $\left[s^{*}(0), s^{*}(1)\right]$. Indeed, I will show later that no firm would find it optimal to choose a product outside this interval, in equilibrium.

PROPOSITION 3. $s^{*}(\cdot)$ is a strictly increasing function. Furthermore, for any $n \geq 1$, if $s^{*}(0)<s_{1}<\ldots<s_{n}<s^{*}(1)$, then each product can be guaranteed a positive market share.

I have so far not specified the lower and upper substitutes, but it seems natural now that the upper substitute be located at $s^{*}(1)$ and priced at $c\left(s^{*}(1)\right)$ and the lower substitute located at $s^{*}(0)$ and priced at $c\left(s^{*}(0)\right)$; this would guarantee each firm a positive market share in any equilibrium. ${ }^{7}$ The idea of having these substitutes is to capture the possibility of consumers switching product classes. The lower substitute can be interpreted as the choice of "doing nothing" (consuming the numéraire), and is basic to any partial equilibrium model such as mine. The upper substitute, however, is peculiar to this model where the products are interpreted as qualities; one can think of it as a product class higher in quality to any products that the firms in the differentiated product class can provide-just think of the speeds of cars and airplanes. Formally, the difference between the substitutes and the differentiated products

${ }^{7}$ The case where the lower substitute gets sero market share in equilibrium has been analy zed by Shaked and Sutton (1982) under the no marginal costs assumption. 
is precisely that the prices of the substitutes can be taken as constant by the firms in the differentiated product class. In what follows, I shall refer to the situation where there is only the lower substitute as the one-substitute case and the situation with both lower and upper substitutes as the two-substitutes case. And we now fix the feasible set of products for each firm in the duopoly as $\left[s^{*}(0), s^{*}(1)\right]$ and $\left[s^{*}(0), \infty\right)$ in the two-substitutes case and one-substitute case, respectively-and later (Proposition 4) we show that this difference between the two cases is inconsequential because choosing a product from $\left[s^{*}(0), s^{*}(1)\right]$ is a dominant strategy for each firm even in the one-substitute case. The key difference between the two cases is that the upper maiket boundary of the higher quality firm is (identically) 1 in the one-substitute case, whereas it is less than 1 in the two-substitutes case.

\section{PERFECT PRODUCT-PRICE EQUILIBRIUM}

The game among the 2 firms is defined as follows. First, each firm chooses a product $s_{i} \in P=\left[s^{*}(0), s^{*}(1)\right]$, simultaneously. Next, having observed the product choice of the other firm (and of course its own), each firm chooses a price $p_{i} \in\left[c\left(s_{i}\right), u\left(1, s_{i}\right)\right]$, simultaneously. The game is one of imperfect information because the firms move simultaneously, whenever they move. (The assumption of "simultaneous moves" doesn't really require the firms to move at the same time, only that whenever each firm makes a move it is not aware of the corresponding move of the other firm.) I assume complete information, which in this context means that the demand structure and the firms' cost functions are common knowledge among the firms. Because the game has more than one move, we need some concept of "perfectness" of equilibrium to avoid equilibria sustained by spurious second-move threats (cf. Selten, 1975). ${ }^{8}$

${ }^{8}$ Some notation. Pairs will be denoted by their distinguishing character (e.g., $s^{0}=$ $\left.\left(s_{1}^{0}, s_{2}^{o}\right)\right)$ and the strategies of the firm other than $i$ will carry the subscript $-i$ (e.g., if $i=1$, then $s_{-1}=s_{2}$ ). Also, I will freely use the semi-colon in a function argument to separate what is fixed from what is variable. 
DEFINITION. A pure perfect product-price equilibrium (pure PPPE) is a pair of products $s^{0} \in P^{2}$ and a pair of price functions $p^{0}=\left(p_{1}^{0}: P^{2} \rightarrow\left[c\left(s_{1}^{0}\right), u\left(1, s_{1}^{0}\right)\right]\right.$, $\left.p_{2}^{0}: P^{2} \rightarrow\left[c\left(s_{2}^{0}\right), u\left(1, s_{2}^{0}\right)\right]\right)$, that satisfy, for $i=1,2$ :

1. For all $s \in P^{2}, p_{i} \in\left[c\left(s_{i}\right), u\left(1, s_{i}\right)\right]: \quad \Pi_{i}\left(s_{i}, p_{i}^{0}(s) ; s_{-i}, p_{-i}^{0}(s)\right) \geq \Pi_{i}\left(s_{i}, p_{i} ; s_{-i}, p_{-i}^{0}(s)\right)$,

2. For all $s_{i} \in P: \Pi_{i}\left(s_{i}^{0}, p_{i}^{0}\left(s^{0}\right) ; s_{-i}^{0}, p_{-i}^{0}\left(s^{0}\right)\right) \geq \Pi_{i}\left(s_{i}, p_{i}^{0}\left(s_{i}, s_{-i}^{0}\right) ; s_{-i}^{0}, p_{-i}^{0}\left(s_{i}, s_{-i}^{0}\right)\right)$.

(A mixed PPPE is a pair of probability measures on the product spaces and a pair of price functions that yield probability measures on the price spaces, such that conditions (1) and (2) above are satisfied in expectation with respect. to the product measure.)

The definition of a PPPE imposes the stringent requirement that for every choice of products by the two firms-including those not actually chosen in equilibrium-the prices that follow must be equilibrium prices; notice that in condition (2) of the definition product deviations such as $s_{i}$ (from the equilibrium $s_{i}^{0}$ ) are evaluated using the equilibrium price functions $p^{0}$. This rules out incredible threats. Thus, a firm can't say: "If you choose product $A$, then I will choose product $B$ and price $C$, which will hurt you ...," unless price $C$ were in fact an equilibrium best-response for the firm in the price game generated by (A, B). An implicit assumption in the definition of a PPPE is that a price equilibrium exists for any pair of products. (If the price equilibrium didn't exist the firms wouldn't know how to compute their profits from a given product strategy.) Also, if there were multiple price equilibria each of them would be associated with a separate PPPE. A sufficient condition for existence and uniqueness of the price equilibrium (in conjunction with the assumptions of Section 3) is Assumption 4.1 below.

Define $S=\left\{\left(s_{1}, s_{2}\right): s^{*}(0)<s_{1}<s_{2}<s^{*}(1)\right\}$, and for $s \in S$, define $\mathcal{P}(s)=\left\{\left(p_{1}, p_{2}\right) \in X_{i=1}^{2}\left[c\left(s_{i}\right), u\left(1, s_{i}\right)\right]:(s, p)\right.$ induces a positive market share to each firm $\}$. (Proposition 3 guarantees that each of these sets is nonempty.) For $(s, p) \in S \times P(s)$, the market share of any firm $i$ with $s_{1}<s_{2}$ is given by $m_{i}(s, p)=t_{i+1}-t_{i}$ in the two-subsitutes case, where $t_{i}$ is defined by $u\left(t_{i}, s_{i}\right)-$ $p_{i}=u\left(t_{i}, s_{i-1}\right)-p_{i-1}$; the only difference in the one-substitute case is that $t_{3} \equiv 1$. We note straightaway that $m_{i}$, and the profit function $\Pi_{i}(s, p)=$ $m_{i}(s, p)\left(p_{i}-c\left(s_{i}\right)\right)$, are continuous functions of $(s, p)$, for $(s, p) \in S \times P(s)$. ( $\Pi_{i}$ is not continuous for $s \notin S$ : the points of discontinuity are along the rays $s_{1}=s_{2}, p_{1}=p_{2}$.) Furthermore, Assumption 4.1 below implies that $\Pi_{i}$ is a 
strictly quasi-concave function of $p_{i}$ on $S \times P(S) .^{9}$

ASSUMPTION 4.1: For $i=1,2,(s, p) \in S \times P(s), \partial^{2} \Pi_{i} / \partial p_{i} \partial p_{i-1} \geq 0, \partial^{2} \Pi_{i} / \partial p_{i} \partial p_{i+1} \geq$ 0 , and $\max \left(\partial^{2} \Pi_{i} / \partial p_{i} \partial p_{i-1}, \partial^{2} \Pi_{i} / \partial p_{i} \partial p_{i+1}\right)>0$, at the critical points of $\Pi_{i}\left(\cdot ; s, p_{-i}\right)$.

(In the one-substitute case, clearly $\partial^{2} \Pi_{2} / \partial p_{2} \partial p_{3}=0$.)

Essentially, Assumption 4.1 requires that the best-price of either firm increase with the prices of its neighbors.

LEMMA 1. For $(s, p) \in S \times P(s), \Pi_{i}$ is strictly quasi-concave in $p_{i}$ for $i=1,2$.

Note from the last line of the proof that strict concavity of $\Pi_{i}$ with respect to $p_{i}$ does not imply Assumption 4.1-and we need this assumption in the uniqueness theorem. Furthermore, $\left|\partial^{2} \Pi_{i} / \partial p_{i}^{2}\right|<\max \left\{\partial^{2} \Pi_{i} / \partial p_{i} \partial p_{i-1}, \partial^{2} \Pi_{i} / \partial p_{i} \partial p_{i+1}\right\}$ at the critical points.

We define the best-price correspondence for $i(i=1,2)$ as ${ }^{10}$

$$
p_{i}\left(p_{-i} ; s\right)=\underset{p \in \in\left[\left(s_{i}\right), u\left(1, s_{i}\right)\right]}{\operatorname{argmax}} \Pi_{i}(p ; s) \quad \text { for }(s, p) \in S \times P(s) .
$$

THEOREM 1. There exists a pure price equilibrium, continuous in $s$, for any $s \in P^{2}$.

It might be wondered what enables existence of a pure price equilibrium in my model for all product locations of the two firms, unlike the Hotelling (1929) model. The reason is that the profit functions are strictly quasi-concave in the respective prices- -80 that there is a unique best-price for any price of the other firm. This depends in turn on the fact that consumer tastes for the product attribute are distributed continuously; thus, when the products are distinct and chosen from $P$ market share varies continuously with price, and no firm can be undercut-and that includes the substitute(s).

THEOREM 2. The pure price equilibrium is unique for any $s \in P^{2}$.

Having shown the existence and uniqueness of a pure price equilibrium with Assumption 4.1 we now turn to the product equilibrium. In the two-substitutes

${ }^{9}$ A function $f: A \rightarrow B$ is strictly quasi-concave if $A$ is convex and $f\left(\alpha a_{1}+(1-\alpha) a_{2}\right)>$ $\min \left(f\left(a_{i}\right), f\left(a_{2}\right)\right)$ for $\alpha \in(0,1)$. In general, strictly quasi-concave functions are singie-peaked functions.

${ }^{10} \mathrm{~A}$ correspondence is merely a set-valued function. By $\operatorname{argmax}_{x \in A} f(x)$ I mean the set of maximizers of $f$ over $A$. 
case, since the upper substitute is located at $s^{*}(1)$, the product choices of each firm are necessarily restricted to $P$. But what about the one-substitute case? 1 show below that choosing a product from within $P$ is a dominant strategy for each firm.

PROPOSITION 4. The best-response of any firm to the product strategy of the other firm is to choose a product from $P$.

The idea behind the proof of Proposition 4 is worth keeping in mind. Proposition 3 tells us that interval of consumers' favorite products (under marginal cost pricing) is $P$. So if a firm chooses a product from outside of $P$ it is not efficiently placed to serve any consumer: By an appropriate choice of product from $P$, it can realize a higher margin while serving the same segment.

Thus we can restrict each firm's product choices to $P$, even in the onesubstitute case. Let $\Pi_{i}^{0}(s) \equiv \Pi_{i}\left(s_{i}, p_{i}^{0}(s), s_{-i}, p_{-i}^{0}(s)\right)$, denote the profit function of $i$ as a function of products alone (with the price equilibrium substituted in). The best-product correspondence for $i(i=1,2)$ is defined as follows:

$$
b_{i}\left(s_{-i}\right)=\underset{i, \in P}{\operatorname{argmax}} \Pi_{i}^{0}(s) \quad \text { for } s_{-i} \in P .
$$

THEOREM 3. There exists a mixed PPPE.

We see that existence of a mixed PPPE isn't really much of a problem in my model. Essentially existence of a mixed equilibrium depends on continuity of the payoff functions of the players (although see Dasgupta and Maskin (1982a) for a relaxation of this requirement) and by making the game two-stage, I make the $\Pi_{i}^{0}$ functions continuous in $s$ even though the underlying $\Pi_{i}$ are not. Recall that it is lack of continuity of the $\Pi_{i}$ with respect to $(s, p)$ that precludes existence of an equilibrium in the game with simultaneous choice of products and prices.

I have proved existence of a mixed PPPE through global fixed-point arguments and one might be tempted to look for a pure equilibrium using these same methods. But here we are doomed to failure. An essential requirement of the Debreu (1952) existence theorem (cf. Appendix 2) is quasi-concavity of the $\prod_{i}^{i}$ with respect to $s_{i}(i=1,2)$, and $\Pi_{i}^{i}$ is certainly not quasi-concave in my mode!: If $s_{i}$ is distinct then $\Pi_{i}^{0}>0$, whereas if $s_{i}=s_{j}$ for some $j \neq i, \Pi_{i}^{0}=0$. Actually, it is not so much the lack of quasi-concavity as the possibility that the 
best-response correspondence may not be $\infty$ nvex-valued, ${ }^{11}$ that is particularly damaging - it may well be that there is always a unique best-response for every firm, and then one could use Brouwer's fixed-point theorem (cf. Appendix 2) on the best-product functions.

But intuition suggests that the best-product correspondence will not be convex-valued in this model. For every product of one firm in the interior of $P$, the other firm can choose a product of lower or higher quality. Then, if one firm chooses a "low" quality, it seems reasonable that the other firm should. choose a higher quality -if it chose a lower quality then the two firms would be too close to each other and vigorous price competition will follow-but as the lower firm moves closer to the upper firm, at first the upper firm will move further up-trying to get away from the lower firm-but eventually it would want to "jump" below the lower firm. (In the one-substitute case this is simply because the upper firm starts to lose market share rapidly as its price increases to support the higher costs; in the two substitutes case there is the additional aspect of getting closer to the upper substitute.) One expects then a point $\xi \in$ $P$ such that, if one firm has a product at $\xi$ the other firm is indifferent between moving up or down whereas, if the firm is above (below) $\xi$, the other firm wants to be below (above). Figure 3 expresses this. $g(\cdot)$ represents the best-responses of a firm when it is constrained to choose a product of lower quality than the other firm, and $f(\cdot)$ represents the constrained upper best-responses. Notice that both $g$ and $f$ are continuous and that at the point $\xi$, there is a downward jump (from the left)-it is at this point that there is a nonconvexity, the global best response to $\xi$ is the nonconvex $\operatorname{set}\{g(\xi), f(\xi)\}$.

The literature has at least two existence theorems that "get around" nonconvexities of this sort, but neither helps with Figure 3 . Roberts and Sonnenschein (1976) have an existence theorem for symmetric firms that handles upward jumps from the lett, but not downward jumps. Nor is Nishimura and Friedman (1981) applicable because their central condition (A4) is violated here: If firm 1 chooses $\xi$ then firm 2's best response is $\{g(\xi), f(\xi)\}$, but for 2 choosing $\xi \in\{g(\xi), f(\xi)\}$ firm 1's best response $\{g(\xi), f(\xi)\}$ straddles its initial position $\xi$. My main result is Theorem 4, an existence theorem for the situation

\footnotetext{
${ }^{11}$ Quasi-coneavity is sufficient for convex-valued best-response correspondences, but not necessary.
} 
Figure 3. The best-product correspondence

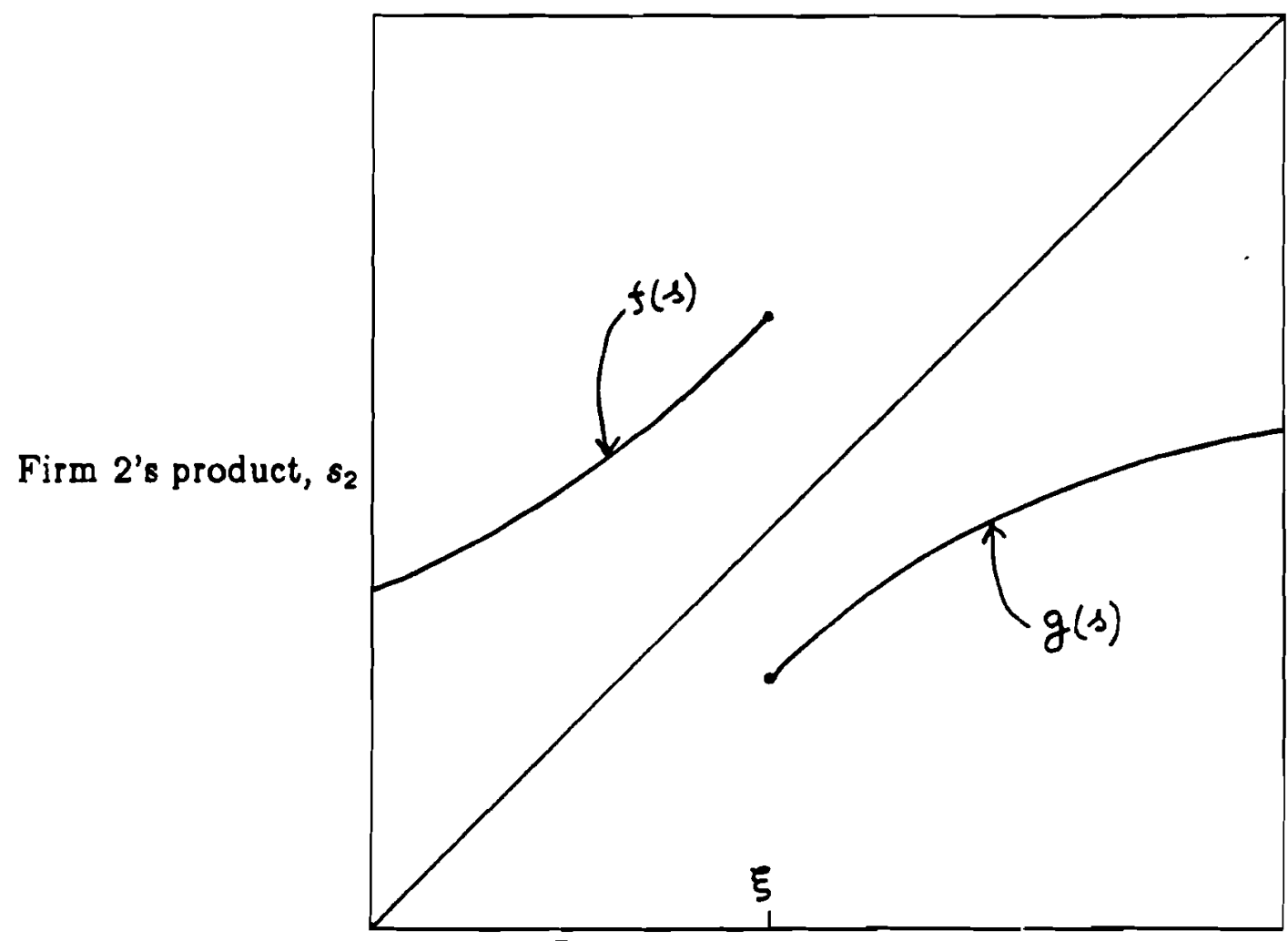

Firm 1's product, $\boldsymbol{s}_{1}$

represented by Figure 3. The proof is based on Brouwer's fixed-point theorem stated in Appendix 2.

In a symmetric duopoly $\Pi_{1}^{\circ} \equiv \Pi_{2}^{\circ}$ and we shall denote this function by $\Pi^{\circ}$. Then for $s \in P$ the constrained best-product correspondences are defined as follows:

$$
\begin{aligned}
& g(s)=\underset{s, \in\left[s^{*}(0), s\right]}{\operatorname{argmax}} \Pi^{0}\left(s_{1}, s\right) \\
& f(s)=\underset{s, \in\left[s, s^{*}(1)\right]}{\operatorname{argmax}} \Pi^{0}\left(s_{1}, s\right)
\end{aligned}
$$

I note straightaway that for $s \in\left(s^{*}(0), s^{*}(1)\right), g(s)<s$ and $\left.f(s)\right\rangle s$ (cf. Proposition 3). I state Theorem 4 abstractly by specifying the symmetric duopoly as the collection $\left\langle P, \Pi^{\circ}\right\rangle$ where $P$ is the common strategy space and $\Pi^{\circ}$ is the common payoff function. 
THEOREM 4. Suppose a symmetric duopoly $\left\langle P, \Pi^{\circ}\right\rangle$ satisfies the following conditions:

1. $P \subset \Re$ is a compact interval $[p, \bar{p}], p<\bar{p}$.

2. $g$ and $f$, the constrained best-response correspondences, are continuous functions on $P$ and for $s \in(p, \bar{p}), g(s)<s$ and $f(s)>s$.

3. There exists an $\xi \in(p, \bar{p})$ such that $\left\{s \in P: \Pi^{\circ}(f(s), s) \geq \Pi^{\circ}(g(s), s)\right\}=$ $[\boldsymbol{p}, \boldsymbol{\xi}]$.

4.

$$
\begin{aligned}
& g(\bar{p})>\xi \Rightarrow g(f(\xi)) \leq \xi \\
& f(p)<\xi \Rightarrow f(g(\xi)) \geq \xi
\end{aligned}
$$

Then there exists at least a pair of pure asymmetric Nash equilibria.

COROLLARY. Even if condition (4) is not satisfied, there exists a symmetric mixed Nash equilibrium with both firms randomising between $g(\xi)$ and $f(\xi)$.

Conditions (2) and (3) express formally what has already been discussed in connection with Figure 3 . In particular, (3) is implied by the following properties of $\Pi^{0}:(1) \Pi^{\circ}$ is continuous. (2) $\Pi^{0}\left(g\left(s^{*}(0)\right), s^{*}(0)\right)<\Pi^{\circ}\left(f\left(s^{*}(0)\right), s^{*}(0)\right)$ and $\Pi^{\circ}\left(f\left(s^{*}(1)\right), s^{*}(1)\right)<\Pi^{\circ}\left(g\left(s^{*}(1)\right), s^{*}(1)\right)$. (3) $\partial \Pi^{\circ}\left(s_{1}, s_{2}\right) / \partial s_{2}<0(>0)$ for $s_{2}<s_{1}$ (respectively, $s_{2}>s_{1}$ ). The first two conditions are already satisfied in our model, and the last one is intuitively compelling. Note that it is weaker than requiring that $g$ and $f$ be increasing functions. Condition (4) of the theorem also has an appealing intuitive interpretation. It says, essentially, that from a starting strategy $\xi$, where both firms are indifferent between moving up (to $f(\xi)$ ) and moving down (to $g(\xi)$ ), if one firm chooses to move up (down), the other firm would respond optimally by moving down (up). Consider what might happen if this condition were violated, i.e., suppose $g(f(\xi))>\xi$ and $f(g(\xi))<\xi$. Then, if $s_{2}=f(\xi), b_{1}\left(s_{2}\right)=g(f(\xi))>\xi$, $b_{2}\left(b_{1}\left(s_{2}\right)\right)=g(g(f(\xi))) \ll \xi$, and $b_{1}\left(b_{2}\left(b_{1}\left(s_{2}\right)\right)\right)=f(g(g(f(\xi)))) \approx \xi !$ and we start another cycle firm 2 's response. In the mixed equilibrium, the randomization of one firm between $g(\xi)$ and $f(\xi)$ must "approximate" $\xi \in(g(\xi), f(\xi)$ ), because the other firm is indifferent between $g(\xi)$ and $f(\xi)$. Another thing to note is that even though the theorem is stated in terms of a symmetric duopoly, it is easily modified to account for asymmetries between the firms such as those arising from differences in the cost functions; then each firm will have its own $\xi$, say $\xi_{1}$ and $\xi_{2}$, and (4) will have $g_{2}(\bar{p})>\xi_{2} \Rightarrow g_{2}\left(f_{1}\left(\xi_{1}\right)\right)<\xi_{1}$, 
etc. Extension of the theorem to more than two firms is not easy though, and I will discuss some of the problems in Section 7.

In the next two sections I discuss in succession the one-substitute and two-substitute cases for an example where the conditions of Theorem 4 are satisfied.

\section{AN EXAMPLE (ONE-SUBSTITUTE CASE)}

I specify the example as: $u(t, s)=t s, c(s)=\alpha s^{2}(\alpha \in(0,1), H(t)=t$ on $[0,1]$. Then $s^{*}(0)=0$ and $s^{*}(1)=1 / 2 \alpha$. (The consumer side of this example is identical to the models of Bresnahan (1981), Gabszewicz and Thisse (1979, 1980), and Shaked and Sutton (1982).)

I determine the price equilibrium first. If $s_{1}=s_{2}$, then the classical Bertrand equilibrium holds: $p_{1}^{0}=p_{2}^{o}=\alpha s_{1}^{2}$. If $0<s_{1}<s_{2}<1 / 2 \alpha$, then for $p \in P(s)$, the profit function of either firm can be written as $\Pi_{i}(p ; s)=$ $\left(t_{i+1}-t_{i}\right)\left(p_{i}-\alpha s_{i}^{2}\right)$ where $t_{i}=\left(p_{i}-p_{i-1}\right) /\left(s_{i}-s_{i-1}\right)$ for $i=1,2$ and $t_{3} \equiv 1$. Since the profit functions are quadratic functions in the prices, Assumption 4.1 is satisfied and a unique price equilibrium exists. It is given by the following first-order conditions:

$$
\begin{aligned}
& \left(p_{1}^{0}-\alpha s_{1}^{2}\right)\left(\frac{s_{2}}{s_{1}\left(s_{2}-s_{1}\right)}\right)-\left(\frac{p_{2}^{0}-p_{1}^{0}}{s_{2}-s_{1}}-\frac{p_{1}^{0}}{s_{1}}\right)=0 \text {, } \\
& \left(p_{2}^{0}-\alpha s_{2}^{2}\right)\left(\frac{1}{s_{2}-s_{1}}\right)-\left(1-\frac{p_{2}^{0}-p_{1}^{0}}{s_{2}-s_{1}}\right)=0 .
\end{aligned}
$$

Solving for $p_{i}^{\circ}$ and $p_{2}^{\text {? }}$ we get:

$$
\begin{aligned}
p_{1}^{0} & =\left(\frac{s_{1}}{4 s_{2}-s_{1}}\right)\left(s_{2}-s_{1}+\alpha s_{2}^{2}+2 \alpha s_{1} s_{2}\right) \\
p_{2}^{0} & =\left(\frac{2 s_{2}}{4 s_{2}-s_{1}}\right)\left(s_{2}-s_{1}+\alpha s_{2}^{2}+\frac{1}{2} \alpha s_{1}^{2}\right), \\
p_{1}^{0}-\alpha s_{1}^{2} & =\frac{s_{1}\left(s_{2}-s_{1}\right)}{\left(4 s_{2}-s_{1}\right)}\left(1+\alpha\left(s_{2}-s_{1}\right)\right) \\
p_{2}^{\circ}-\alpha s_{2}^{2} & =\frac{2 s_{2}\left(s_{2}-s_{1}\right)}{\left(4 s_{2}-s_{1}\right)}\left(1-\alpha\left(s_{2}+\frac{s_{1}}{2}\right)\right) \\
m_{1}^{0} & =\left(\frac{s_{2}}{4 s_{2}-s_{1}}\right)\left(1+\alpha\left(s_{2}-s_{1}\right)\right)=\left(\frac{2 s_{2}}{4 s_{2}-s_{1}}\right) K_{1}\left(s_{1}, s_{2}\right) \\
m_{2}^{0} & =\left(\frac{2 s_{2}}{4 s_{2}-s_{1}}\right)\left(1-\alpha\left(s_{2}+\frac{s_{1}}{2}\right)\right)=\left(\frac{2 s_{2}}{4 s_{2}-s_{1}}\right) K_{2}\left(s_{1}, s_{2}\right)
\end{aligned}
$$


where $K_{1}\left(s_{1}, s_{2}\right)$ (respectively, $K_{2}\left(s_{1}, s_{2}\right)$ ) is the market share of firm 1 (respectively, firm 2) when it prices at marginal cost and the other firm responds optimally Observe that $m_{1}^{0}, m_{2}^{0}, p_{1}^{0}-\alpha s_{1}^{2}$, and $p_{2}^{0}-\alpha s_{2}^{2}$, and hence the profits, are positive for $s_{1}, s_{2} \in[0,1 / 2 \alpha]$.

Some properties of the price equilibrium are worth noting. The price of the upper firm is increasing in its quality-not surprising given that consumers are willing to pay more for higher quality, the firm's costs are increasing, and it is getting away from the competition. For the lower firm, price is a unimodal function of its quality-the decreasing part due to the increasing closeness to the higher quality firm. The market share of firm 2 is decreasing in $s_{2}$ everywhere-again not surprising since its price is increasing. For the lower firm, if $s_{2}>1 / 3 \alpha$, market share decreases with quality, if $s_{2}<1 / 3 \alpha$, market share increases with quality, and if $s_{2}=1 / 3 \alpha$, market share is constant at $1 / 3$. We see again the effect of competition on the lower firm when $s_{2}<1 / 3 \alpha-$ moving closer to the upper firm intensifies the price competition because at these low quality levels firm 2 responds aggressively (due to its low costs). (We note that if marginal costs were zero, getting closer to the competition always increases market share. Also, $1 / 3 \alpha$ is the monopolist's (efficient) product location for one product (cf. Moorthy (1983)) and $\alpha s_{2}$ is the market share for firm 1 when both 1 and 2 are pricing at marginal cost.)

Using the price equilibrium, the profit function of either firm can be written as:

$$
\Pi^{o}\left(s_{1} ; s_{2}\right)= \begin{cases}s_{2} s_{1}\left(s_{2}-s_{1}\right)\left(\frac{1+\alpha\left(s_{2}-s_{2}\right)}{4 s_{2}-s_{1}}\right)^{2}, & s_{1}<s_{2} \\ 0, & s_{1}=s_{2} \\ \left(s_{1}-s_{2}\right)\left(\frac{2 s_{2}\left(1-\alpha\left(s_{1}+\left(s_{2} / 2\right)\right)\right)}{4 s_{1}-s_{2}}\right)^{2}, & s_{1}>s_{2} .\end{cases}
$$

This profit function corresponds to the revenue function $R$ of Shaked and Sutton (1982). However, its properties are quite different-which makes the ensuing proofs much harder-from their's: First, it is not true here that both firms would like to choose the higher quality regardless of where the other firm is located. For example, recalling Figure 3 , if $s_{2}>\xi$, then firm 1 would rather be the lower quality. Second, not both firms are always made better off by the upper firm moving upward. Recall that the margin of the upper firm is decreasing at large qualities and its market share is decreasing everywhere. As a consequence, as we shall soon discover, the equilibrium here does not involve 
the upper firm producing its maximum feasible quality.

I will now verify in succession the conditions of Theorem 4 .

PROPOSITION 5. $g$ is a strictly increasing continuous function.

PROPOSITION 6. $f$ is a strictly increasing continuous function.

PROPOSITION 7. There exists a $\xi \in(0,1 / 2 \alpha)$ such that $\left\{s \in[0,1 / 2 \alpha]: \Pi^{\circ}(f(s), s)\right.$ $\left.\geq \Pi_{o}(g(s), s)\right\}=[0, \xi]$.

PROPOSITION 8. $\xi<(1 / 3 \alpha)=f(0)$ and $g(f(\xi))<\xi$.

PROPOSITION 9. There exists a pair of pure asymmetric perfect product-price equilibria in the example.

I have computed the pure equilibria numerically and one of them has $s_{1}^{i} \approx$ $.2 / \alpha, s_{2} \approx .415 / \alpha, p_{1}^{0} \approx .076 / \alpha, p_{2}^{0} \approx .232 / \alpha, \Pi_{1}^{0} \approx .036 / \alpha$ and $\Pi_{2}^{0} \approx .059 / \alpha$. (The other pure equilibrium has $s_{1}^{0} \approx .415 / \alpha, s_{2}^{0} \approx .2 / \alpha$, etc.) Note that the two firms shy away from each other-unlike Hotelling's (1929) model-and each makes positive profits, as a result. Furthermore, the upper firm makes larger profits than the lower firm because it doesn't face competition on one side-there is no upper substitute. Finally, the products are not efficiently placed-the efficient placement is $(.2 / \alpha, .4 / \alpha)$ (cf. Moorthy (1983)).

\section{THE TWO-SUBSTITUTES CASE}

We now have an upper substitute at $1 / 2 \alpha$ and it will have positive market share in equilibrium. Thus both firms face competition from both sides. I will start with the price equilibrium.

For $0<s_{1}<s_{2}<1 / 2 \alpha$, the first-order conditions for a price equilibrium now become:

$$
\begin{aligned}
\left(p_{1}^{0}-\alpha s_{1}^{2}\right)\left(\frac{s_{2}}{s_{1}\left(s_{2}-s_{1}\right)}\right)-\left(\frac{p_{2}^{0}-p_{1}^{0}}{s_{2}-s_{1}}-\frac{p_{1}^{0}}{s_{1}}\right) & =0, \\
\left(p_{2}^{0}-\alpha s_{2}^{2}\right)\left(\frac{s_{3}-s_{1}}{\left(s_{3}-s_{2}\right)\left(s_{2}-s_{1}\right)}\right)-\left(\frac{p_{3}^{0}-p_{2}^{\circ}}{s_{3}-s_{2}}-\frac{p_{2}^{\circ}-p_{1}^{0}}{s_{2}-s_{1}}\right) & =0 .
\end{aligned}
$$


where, of course, $s_{3}=1 / 2 \alpha$ and $p_{3}^{0}=\alpha s_{3}^{2}$. The price equilibrium is:

$$
p_{1}^{i}=\left(\frac{\alpha s_{1}}{4 s_{2}\left(s_{3}-s_{1}\right)-s_{1}\left(s_{3}-s_{2}\right)}\right)\left(s_{3}\left(s_{2}^{2}-s_{1} s_{3}\right)+s_{2}^{2}\left(s_{3}-s_{1}\right)+2 s_{1} s_{2}\left(s_{3}-s_{1}\right)\right) \text {, }
$$

$p_{2}^{0}=\left(\frac{2 \alpha s_{2}}{4 s_{2}\left(s_{3}-s_{1}\right)-s_{1}\left(s_{3}-s_{2}\right)}\right)\left(s_{3}\left(s_{2}^{2}-s_{1} s_{3}\right)+s_{2}^{2}\left(s_{3}-s_{1}\right)+(1 / 2) s_{1}^{2}\left(s_{3}-s_{2}\right)\right)$.

$$
\begin{aligned}
& p_{1}^{0}-\alpha s_{1}^{2}=\frac{\alpha s_{1}\left(s_{2}-s_{1}\right)\left(s_{3}-s_{1}\right)\left(s_{3}+s_{2}\right)}{4 s_{2}\left(s_{3}-s_{1}\right)-s_{1}\left(s_{3}-s_{2}\right)} \\
& p_{2}^{0}-\alpha s_{2}^{2}=\frac{\alpha s_{2}\left(s_{2}-s_{1}\right)\left(s_{3}-s_{2}\right)\left(2 s_{3}-s_{1}\right)}{4 s_{2}\left(s_{3}-s_{1}\right)-s_{1}\left(s_{3}-s_{2}\right)}
\end{aligned}
$$

Note that the margins and market shares are symmetric in the sense that $p_{1}^{0}\left(s_{1}, s_{2}\right)-\alpha s_{1}^{2}=p_{2}^{0}\left(s_{3}-s_{1}, s_{3}-s_{2}\right)-\alpha\left(s_{3}-s_{1}\right)^{2}$ and $m_{1}^{0}\left(s_{1}, s_{2}\right)=m_{2}^{0}(1-$ $\left.s_{1}, 1-s_{2}\right)$. The prices are increasing functions of the respective product qualities, the margins are unimodal functions, and the market shares of firms 1 and 2 are increasing and decreasing functions, respectively. The profit function $\Pi^{\circ}$ is

$$
\Pi^{\circ}\left(s_{1}, s_{2}\right)= \begin{cases}\left(\frac{\left(s_{2}-s_{1}\right) s_{1}}{s_{2}}\right)\left(\frac{\alpha s_{2}\left(s_{3}+s_{2}\right)\left(s_{3}-s_{1}\right)}{4 s_{2}\left(s_{3}-s_{1}\right)-s_{1}\left(s_{3}-s_{2}\right)}\right)^{2}, & s_{1}<s_{2} \\ 0, & s_{1}=s_{2} \\ \left(\frac{\left(s_{1}-s_{2}\right) s_{2}}{s_{1}}\right)\left(\frac{\alpha s_{3}\left(s_{3}+s_{2}\right)\left(s_{3}-s_{2}\right)}{s_{1}\left(s_{3}-s_{2}\right)-s_{2}\left(s_{3}-s_{1}\right)}\right)^{2}, & s_{1}>s_{2}\end{cases}
$$

The product choices with $s_{1}<s_{2}$ are given by the following first-order conditions:

$$
\begin{array}{r}
\left(s_{2}-2 s_{1}\right)\left(s_{3}-s_{1}\right)+\frac{2 s_{1}\left(s_{2}-s_{1}\right)\left(s_{3}-s_{2}\right)}{4 s_{2}\left(s_{3}-s_{1}\right)-s_{1}\left(s_{3}-s_{2}\right)}=0 \\
s_{2}\left(\left(s_{3}-s_{2}\right)-\left(s_{2}-s_{1}\right)\right)-\frac{2 s_{1}\left(s_{2}-s_{1}\right)\left(s_{3}-s_{2}\right)}{4 s_{2}\left(s_{3}-s_{1}\right)-s_{1}\left(s_{3}-s_{2}\right)}=0 .
\end{array}
$$

It is easy to see that $f(0)=s_{3} / 2, g\left(s_{3} / 2\right)=1-f\left(s_{3} / 2\right)$, and $\Pi^{\circ}\left(g\left(s_{3} / 2\right), s_{3} / 2\right)=$ $\Pi^{\circ}\left(f\left(s_{3} / 2\right), s_{3} / 2\right)$, so that $\xi=s_{3} / 2$-the optimal location for a monopolist 
facing two substitutes! (Recall that in the one-substitute case, $\boldsymbol{\xi}$ was less than the monopoly location.) Also, $g$ and $f$ are increasing and $g\left(f\left(s_{3} / 2\right)\right)<s_{s} / 2$. Hence Theorem 4 applies and a pure PPPE exists.

Another way to show existence of an equilibrium is simply to solve for $s_{1}$ and $s_{2}$ in (6.9)-(6.10)-which is easier here than in the one-substitute case, because $s_{1}+s_{2}=s_{9}$-and then verify whether the solution is an equilibrium. The solution is $s_{1}^{0}=.36 s_{3}, s_{2}^{\circ}=.64 s_{3}, p_{1}^{0}=.1448 \alpha s_{3}^{2}, p_{2}^{0}=.2844 \alpha s_{3}^{2}$, and $\Pi^{\circ}=.0312 \alpha^{2} s_{3}^{3}$. It is easy to check that this solution is a "local" equilibrium i.e., the second-order conditions for maximization are satisfied for the given product ordering, $s_{1}<s_{2}$. However, we still need to make sure that no firm wants to "jump". Suppose firm 1 contemplates moving to $s_{1}^{\prime} \in\left(.64 s_{9}, 1 / 2 \alpha\right)$. Its profits at $s_{1}^{\prime}$ will be

$$
\Pi_{1}^{\prime}\left(s_{1}^{\prime}, s_{2}\right)=\left(\frac{\left(s_{1}^{\prime}-s_{2}\right)\left(s_{3}-s_{1}^{\prime}\right)}{\left(s_{3}-s_{2}\right)}\right)\left(\frac{\alpha\left(s_{3}-s_{2}\right)\left(2 s_{3}-s_{2}\right) s_{1}^{\prime}}{4 s_{1}^{\prime}\left(s_{3}-s_{2}\right)-s_{2}\left(s_{3}-s_{1}^{\prime}\right)}\right)^{2}
$$

where $s_{2}=.64 s_{s}$. Now,

$$
\begin{aligned}
\frac{\left(s_{1}^{\prime}-s_{2}\right)\left(s_{3}-s_{1}^{\prime}\right)}{\left(s_{3}-s_{2}\right)} & \leq \frac{s_{9}-s_{2}}{4} \text { and } \\
\frac{\alpha\left(s_{3}-s_{2}\right)\left(2 s_{3}-s_{2}\right) s_{1}^{\prime}}{4 s_{1}^{\prime}\left(s_{3}-s_{2}\right)-s_{2}\left(s_{3}-s_{1}^{\prime}\right)} & \leq \frac{\alpha\left(2 s_{3}-s_{2}\right)}{3} .
\end{aligned}
$$

Hence, $\Pi_{1}^{\prime}\left(s_{1}^{\prime}, .64 s_{s}\right) \leq .019 \alpha^{2} s_{3}^{3}<.0312 \alpha^{2} s_{3}^{3}$ (using $s_{2}=.64 s_{s}$ ), and firm 1 would not like to jump to the permutation $\left(.64 s_{s}, s_{1}^{\prime}\right)$ from $\left(.36 s_{s}, .64 s_{3}\right)$. Similarly, for the upper firm. Thus we have,

PROPOSITION 10. There exists a pair of pure asymmetric perfect product-price equilibria in the two-substitutes case of the example.

Again, the equilibria do not place the products efficiently, both firms move to the center away from the corresponding substitutes; the efficient placement is $\left(s_{3} / 3,2 s_{3} / 3\right)$.

\section{EXTENSION TO $n>2$ FIRMS}

The propositions and theorems pertaining to the price equilibrium proved in Section 4 extend easily. This is because on the set of product and price $n$-tuples with distinct products and positive market shares for every firm$S \times P(S)$, suitably generalized-each firm's profit function, besides depending 
on its own product and price, depends only on the products and prices of its neighbors. However, as I remarked in Section 4 the PPPE existence theorem for the duopoly (Theorem 4) does not extend easily to $n>2$ firms. Here 1 wish to elaborate why and at the same time suggest a way out.

Consider the method of Theorem 4. For any product configuration of $n-1$ firms, $s_{-i}$, let $f_{i}\left(s_{-i}\right)$ be the best-product for any firm in the ith position, i.e., $s_{1}<\cdots<s_{i-1}<f_{i}\left(s_{-i}\right)<s_{i+1}<\cdots<s_{n}$ and $f_{i}\left(s_{-i}\right)$ maximizes $\Pi^{\circ}$ over $\left[s_{i-1}, s_{i+1}\right]$. We would want to divide up $P$ into $n$ subintervals $\left[b_{0}, b_{1}\right],\left[b_{1}, b_{2}\right], \ldots,\left[b_{n-1}, b_{n}\right]$ with $b_{0} \geq s^{*}(0)$ and $b_{n} \leq s^{*}(1)$ such that for $i=1, \ldots, n: s_{-i} \in X_{j=i}^{n}\left[b_{j-1}, b_{j}\right]$ implies $f_{i}\left(s_{-i}\right) \in\left[b_{i-1}, b_{i}\right]$ is the global best-product for $i$. Suppose $n=5$ and $s_{1}=b_{0}, s_{2}=b_{2}, s_{3}=b_{3}$, and $s_{4}=b_{5}$. Is $f_{2}\left(s_{1}, s_{2}, s_{3}, s_{4}\right) \in\left[b_{1}, b_{2}\right]$ or $f_{4}\left(s_{1}, s_{2}, s_{3}, s_{4}\right) \in\left[b_{3}, b_{4}\right]$, the best-product? This ambiguity makes using fixed-point theorems dificult.

But I think there is a way to use an induction argument to extend the theorem. First, it is easy to show in most cases that the "local" profit functionsthe restrictions of the profit functions to the space between neighboring productsare concave in the respective products. Then the $f_{i}$ exist and are continuous, and a local equilibrium exists by Brouwer's fixed-point theorem. Problems arise because firms may wish to change the ordering implied by any $\left(f_{1}, \ldots, f_{n}\right)$. However, if a firm were unwilling to jump from $f_{2}\left(s_{2}\right)$ to $f_{1}\left(s_{2}\right)$ (or $f_{1}\left(s_{2}\right)$ to $f_{2}\left(s_{2}\right)$ ) when $n=2$, then it is unlikely to jump from $f_{1}\left(s_{-1}\right)$ to $f_{3}\left(s_{-1}\right)$, say, with $n=3$. The key is that profits must get more uniformly distributed across the local equilibrium as $n$ increases i.e., $\max _{i, j}\left|\Pi^{\circ}\left(f_{i}\left(s_{-i}\right) ; s_{-i}\right)-\Pi^{\circ}\left(f_{j}\left(s_{-j}\right) ; s_{-j}\right)\right|$ decreases with $n$. This would necessarily happen for large $n$ if the local equilibria converged to full effiency as $n \rightarrow \infty$-the limiting profits of each firm would be zero.

\section{CONCLUSION}

In this paper I analyzed product and price competitition in a duopoly in a dynamic setting. The dynamics arise from the fact that both firms are aware of each other's product when choosing prices. My model is a "qualitychoice" model, by which I mean that firms are competing for segments which differ in their taste for a "quality-like attribute" - some consumers are willing to pay more than others for the same increment in quality, but everyone 
prefers high quality to low quality, ceteris paribus. (The ame model had been analyzed earlier with a monopolist choosing a product line; cf. Moorthy (1983).) The main objective was to verify whether the commonsense notion of competing by "seeking niches" has any theoretical basis, and if so, whether we can say anything about these niches. While this may seem trivial at first glance, careful analysis turns up surprising diffculties. For example, if each firm chooses a quality-price pair at the same time (or without the knowledge of) the other firm, it is difficult to come up with any "optimal strategy" for either firm: if firm $\mathbf{A}$ thought that firm B was going to choose the product $s$ and price $p$ then $A$ would rather choose a product close to $s$ in quality (say $s^{\prime}$ ) and undercut the other firm slightly (with, say, $p^{\prime}$ ), but then A must surely reason that $B$ would not be choosing $(s, p)$, for $B$ could have gone through this same reasoning (while considering $(s, p)$ ) and come up with zero profits. In short, there is no equilibrium when firms compete in this fashion and without an equilibrium we can't say (or at least have no firm basis for saying) whether product differentiation is a good competitive strategy or not.

In my model firms choose products and prices in sequence, first products and then prices. This dynamic setting, besides being more realistic, enables the existence of an equilibrium under relatively weak conditions. (The key reason for this positive result is that now when one firm approaches the other, it anticipates the low prices that will follow in the second stage.) Essentially, existence depends upon each firm having a unique "local" best-product responselocal in the sense of being constrained to be below or above the other firm-for each product position of the other firm, and a boundary condition which has the following intuitive interpretation: If from a position where each firm is indifferent between moving above or below the other firm, one firm chooses to move up (down), then the other firm must move down (up). A basic finding is that whenever the pure equilibrium exists it is asymmetric, i.e. even though the firms are alike, they would like to take up distinct product positions. (This is in contrast to findings in the Hotelling type of model where, typically, two or more firms take up similar positions in the absence of price competition.) I applied my existence theorem to an example and found the equilibria to be inefficient: there is excessive movement away from the substitutes.

The question of existence of a pure equilibrium for more than two firms 
remains unresolved at this stage. I conjecture that $n$-firm equilibria exist if 2-firm equilibria exist. Furthermore, I am pretty certain that these equilibria converge to the efficient solution as the number of firms tends to infinity; the convergence will be due to the increasing substitutability of the products as they become uniformly dense on the product space. One of the problems in proving these conjectures is the relative intractability of product differentiation models: it is difficult to establish the concavity of profit functions from the basic data of the economy-consumer preferences and firms' cost functionsand in some cases, as here, lack of concavity is a generic property. (This point has been underscored by Roberts and Sonnenschein (1977).) But I think there is still value to analyzing simple models, if nothing else, but to learn why things don't work. 


\section{APPENDDX 1}

THE PROOFS

PROOF OF PROPOSITION 1: We note that if $v=H(t)$, then $v$ is uniformly distributed on $[0,1]$. Then, for $v \in[0,1], r \in \Re_{+}$, define

$$
\begin{aligned}
W(v, r) & \equiv u\left(H^{-1}(v), r\right)-u\left(H^{-1}(v), 0\right) \\
B(r) & \equiv c(r)-c(0) .
\end{aligned}
$$

Then $W$ and $B$ satisfy the properties assumed for $u$ and $c$, respectively. PROOF OF PROPOSITION 2: Part (1) is obvious. To prove (2) su ppose $s_{i}<s_{j}$, $t_{i} \in M_{i}, t_{j} \in M_{j}$, and $t_{i}>t_{j}$. Then, using $u_{t=}>0, u\left(t_{i}, s_{j}\right)-u\left(t_{i}, s_{i}\right)>$ $u\left(t_{j}, s_{j}\right)-u\left(t_{j}, s_{i}\right) \geq p_{j}-p_{i}$ so that $t_{i} \notin M_{i}$, a contradiction. Part (3) follows easily from the definition of market segments and the continuity of $u$.

PROOF OF PROPOSITION 3: The monotonicity of $s^{*}$ is obtained by totally differentiating (3.2) with respect to $t$ and using (3.1) and (3.3). As for the second part we note that since $s^{*}$ is strictly increasing, it has an inverse function $t^{*}$ such that $s^{*}\left(t^{*}\left(s_{i}\right)\right)=s_{i}$ for $i=1, \ldots, n$, and

$$
u\left(t^{*}\left(s_{i}\right), s_{i}\right)-c\left(s_{i}\right) \geq u\left(t^{*}\left(s_{i}\right), s_{j}\right)-c\left(s_{j}\right) \quad j=0,1, \ldots, n+1
$$

Hence, by pricing at marginal cost, product $s_{i}$ can assure itself of $t^{*}\left(s_{i}\right)$ and a positive interval surrounding it.

PROOF OF LEMMA 1: We note first that (3.1) implies that:

$$
\begin{aligned}
& \frac{\partial t_{i}}{\partial p_{i}}=-\frac{\partial t_{i}}{\partial p_{i-1}}=\frac{1}{\Delta u_{i}\left(t_{i}\right)}>0, \quad \text { and } \\
& \frac{\partial^{2} t_{i}}{\partial p_{i}^{2}}=\frac{\partial^{2} t_{i}}{\partial p_{i-1}^{2}}=-\frac{\partial^{2} t_{i}}{\partial p_{i} \partial p_{i-1}}=-\frac{\Delta u_{t t}\left(t_{i}\right)}{\left(\Delta u_{t}\left(t_{i}\right)\right)^{3}},
\end{aligned}
$$

where $\Delta u_{t}\left(t_{i}\right)=u_{t}\left(t_{i}, s_{i}\right)-u_{t}\left(t_{i}, s_{i-1}\right)$ and $\Delta u_{t t}=u_{t t}\left(t_{i}, s_{i}\right)-u_{t t}\left(t_{i}, s_{i-1}\right)$. Then:

$$
\begin{aligned}
\frac{\partial^{2} \Pi_{i}}{\partial p_{i}^{2}} & =\left(p_{i}-c\left(s_{i}\right)\right)\left(\frac{\partial^{2} t_{i}}{\partial p_{i} \partial p_{i-1}}-\frac{\partial^{2} t_{i+1}}{\partial p_{i} \partial p_{i+1}}\right)-2\left(\frac{\partial t_{i+1}}{\partial p_{i+1}}+\frac{\partial t_{i}}{\partial p_{i}}\right), \\
\frac{\partial^{2} \Pi_{i}}{\partial p_{i} \partial p_{i-1}} & =-\left(p_{i}-c\left(s_{i}\right)\right)\left(\frac{\partial^{2} t_{i}}{\partial p_{i} \partial p_{i-1}}\right)+\frac{\partial t_{i}}{\partial p_{i}}, \quad \text { and } \\
\frac{\partial^{2} \Pi_{i}}{\partial p_{i} \partial p_{i+1}} & =\left(p_{i}-c\left(s_{i}\right)\right)\left(\frac{\partial^{2} t_{i+1}}{\partial p_{i} \partial p_{i+1}}\right)+\frac{\partial t_{i+1}}{\partial p_{i+1}}
\end{aligned}
$$




$$
\text { Thus, } \frac{\partial^{2} \Pi_{i}}{\partial p_{i}^{2}}=-\left(\frac{\partial^{2} \Pi_{i}}{\partial p_{i} \partial p_{i-1}}+\frac{\partial^{2} \Pi_{i}}{\partial p_{i} \partial p_{i+1}}+\frac{\partial t_{i+1}}{\partial p_{i+1}}+\frac{\partial t_{i}}{\partial p_{i}}\right)<0,
$$

at all the critical points of $\Pi_{i}$ with respect to $p_{i}$, by Assumption 4.1. Hence, $\Pi_{i}$ is strictly quasi-concave with respect to $p_{i}$.

PROOF OF THEOREM 1: We consider first $s \in S$. In this case, $\Pi_{i}$ is continuous in $p$ and the best-price correspondence is a function by Lemma 1 . Consider the function $p^{0}$ defined by $p^{0}(p)=\left(p_{1}^{0}\left(p_{2}\right), p_{2}^{0}\left(p_{1}\right)\right) . p^{0}$ is continuous and has the same (compact and convex) domain and range. Therefore, by Brouwer's. fixed-point theorem it has a fixed-point which is also a pure price equilibrium.

If $s \notin S$, then $s_{i}=s_{j}$ for some $i \neq j$, and the equilibrium price for $i$ and $j$ is $c\left(s_{i}\right)$; for the firms with distinct products, we repeat the previous argument. So again a pure price equilibrium exists.

As for continuity, Berge's (1957) maximum theorem (see Hildenbrand (1974)) yields continuity of the equilibrium on $S$ since $\Pi_{i}$ is a continuous function of $(s, p)$ on $S \times\left[c\left(s_{i}\right), u\left(1, s_{i}\right)\right]$. All that remains is to show that if $s_{i-1} \rightarrow s_{i}$ (say), $p_{i}^{0} \rightarrow c\left(s_{i}\right)$. Observe that the equilibrium on $S$ is obtained by solving the first-order conditions:

$$
\left(p_{i}^{0}-c\left(s_{i}\right)\right)\left(\frac{\partial t_{i+1}}{\partial p_{i}}\left(p_{i}^{0}\right)-\frac{\partial t_{i}}{\partial p_{i}}\left(p_{i}^{0}\right)\right)+\left(t_{i+1}\left(p_{i}^{0}\right)-t_{i}\left(p_{i}^{0}\right)\right)=0 \quad \text { for } i=1,2 .
$$

Note that $\partial t_{i+1} / \partial p_{i}-\partial t_{i} / \partial p_{i}=-\left(\Delta u_{t}\left(t_{i+1}\right)+\Delta u_{t}\left(t_{i}\right)\right) /\left(\left(\Delta u_{t}\left(t_{i+1}\right)\left(\Delta u_{t}\left(t_{i}\right)\right)\right)\right.$ and $\Delta u_{t}\left(t_{i}\right)=u_{t}\left(t_{i}, s_{i}\right)-u_{t}\left(t_{i}, s_{i-1}\right)$, so that $\partial t_{i+1} / \partial p_{i}-\partial t_{i} / \partial p_{i} \rightarrow-\infty$ as $s_{i} \rightarrow s_{i-1}$. Hence, since $\left(t_{i+1}-t_{i}\right)$ is bounded above by $1, p_{i}^{0} \rightarrow c\left(s_{i}\right)$ \&s $s_{i} \rightarrow$ $s_{i-1} \cdot$

PROOF OF THEOREM 2: We consider only the case $s \in S$ since the other cases follow immediately. Then, by the implicit function theorem,

$$
\begin{aligned}
& \frac{\partial p_{i}^{0}}{\partial p_{i-1}}=-\frac{\partial^{2} \Pi_{i} / \partial p_{i} \partial p_{i-1}}{\partial^{2} \Pi_{i} / \partial p_{i}^{2}} \in(0,1) \text { and } \\
& \frac{\partial p_{i}^{0}}{\partial p_{i+1}}=-\frac{\partial^{2} \Pi_{i} / \partial p_{i} \partial p_{i+1}}{\partial^{2} \Pi_{i} / \partial p_{i}^{2}} \in[0,1)
\end{aligned}
$$

$(\in(0,1)$, in the two-substitutes case $)$. Also,

$$
\frac{\partial p_{i}^{0}}{\partial p_{i-1}}+\frac{\partial p_{i}^{0}}{\partial p_{i+1}}=\frac{\partial^{2} \Pi_{i} / \partial p_{i} \partial p_{i-1}+\partial^{2} \Pi_{i} / \partial p_{i} \partial p_{i+1}}{\partial^{2} \Pi_{i} / \partial p_{i} \partial p_{i-1}+\partial^{2} \Pi_{i} / \partial p_{i} \partial p_{i+1}+\partial t_{i+1} / \partial p_{i+1}+\partial t_{i} / \partial p_{i}} \in(0,1) .
$$


Therefore, if $\Delta p_{i-1} \equiv p_{i-1}^{\prime}-p_{i-1} \geq 0$ and $\Delta p_{i+1} \equiv p_{i+1}^{\prime}-p_{i+1} \geq 0$ with $\max \left(\Delta p_{i-1}, \Delta p_{i+1}\right)>0$, then the mean-value theorem implies that

$$
\begin{aligned}
\Delta p_{i}^{0} & \equiv p_{i}^{0}\left(p_{i-1}^{i}, p_{i+1}^{\prime}\right)-p_{i}^{0}\left(p_{i-1}, p_{i+1}\right) \\
& =\left(\Delta p_{i-1}\right)\left(\partial p_{i}^{0} / \partial p_{i-1}\right)+\left(\Delta p_{i+1}\right)\left(\partial p_{i}^{0} / \partial p_{i+1}\right) \\
& \leq \max \left(\Delta p_{i-1}, \Delta p_{i+1}\right)\left(\partial p_{i}^{0} / \partial p_{i-1}+\partial p_{i}^{0} / \partial p_{i+1}\right) \\
& <\max \left(\Delta p_{i-1}, \Delta p_{i+1}\right)
\end{aligned}
$$

where the partial derivatives are evaluated at a point $\hat{p}$ such that $\hat{p}_{i-1} \in$ $\left(p_{i-1}, p_{i-1}^{\prime}\right), \hat{p}_{i+1} \in\left(p_{i+1}, p_{i+1}^{\prime}\right)$. Now suppose there are two price equilibria $\left(p_{1}, p_{2}\right)$ and $\left(p_{1}^{\prime}, p_{2}^{\prime}\right)$ with $p_{1}^{\prime}>p_{1}$. (If $p_{1}^{\prime}=p_{1}$ then, since $\partial p_{1}^{0} / \partial p_{2}>0$, p p $=p_{2}$, and the two equilibria are identical.) Then, since $p_{0}^{\prime}=p_{0}, p_{2}^{\prime}-p_{2}>p_{1}^{\prime}-p_{1}$ (in order for $p_{2}^{\prime}$ to support $p_{1}^{\prime}$ ), and $p_{3}^{\prime}-p_{5}>p_{2}^{\prime}-p_{2}>0$ (in order for $p_{3}^{\prime}$ to support $p_{2}^{\prime}$ ). But $p_{3}^{\prime}=p_{3}=s^{*}(1)$ in the two-substitutes case, so we have a contradiction. In the one-substitute case, $p_{3}^{\prime}-p_{3}=p_{2}^{\prime}-p_{2}=u\left(1, s_{3}\right)-u\left(1, s_{2}\right)$, implicitly, because $t_{3} \equiv 1$, and again we have a contradiction.

PROOF OF PROPOSITION 4: Suppose $i$ chooses a product $s_{i}>s^{*}(1)$ in response to $s_{-i}$ by the other firm. I show below that there exists an alternative product location $s_{i}^{\prime} \in P$ which yields greater profits to $i$. There are two cases.

If $s_{i}$ yields no (price) equilibrium market share then $i$ can certainly do better by choosing a distinct $s_{i}^{\prime} \in P$ (Proposition 3).

If $s_{i}$ yields the positive (price) equilibrium market share segment $\left[t_{i}, t_{i+1}\right]$, $t_{i}<t_{i+1}$, then consider the product $s_{i}^{\prime}=s^{*}\left(t_{i+1}\right)$ at price $p_{i}^{\prime}=u\left(t_{i+1}, s^{*}\left(t_{i+1}\right)\right)-$ $\left(u\left(t_{i+1}, s_{i}\right)-p_{i}\right)$, where $p_{i}$ is the equilibrium price with $s_{i}$. Everyone in $\left[t_{i}, t_{i+1}\right]$ except $t_{i+1}$ (who is indifferent) prefers $\left(s_{i}^{\prime}, p_{i}^{\prime}\right)$ to $\left(s_{i}, p_{i}\right)$. At the same time, $p_{i}^{\prime}-c\left(s_{i}^{\prime}\right)>p_{i}-c\left(s_{i}\right)$. Thus $s_{i}^{\prime}$ must yield greater profits to $i$ in price equilibrium. (Similarly for the case where $s_{i}<s^{*}(0)$.)

PROOF OF THEOREM 3: For each $s \in P^{2}$, Theorems 1 and 2 assert that there exists a unique pure price equilibrium continuous in $s$. Hence, since $\Pi_{i}^{\circ}(s)$ is continuous in $s$ for $i=1,2$ and $P$ is compact, Glicksberg's (1952; cf. Appendix 2) theorem applies.

PROOF OF THEOREM 4: Define $r$ and $F$ as follows:

$$
\tau= \begin{cases}g(\xi), & f(p)<\xi \\ p, & f(p) \geq \xi .\end{cases}
$$




$$
\boldsymbol{F}= \begin{cases}f(\xi), & g(\bar{p})>\xi \\ \bar{p}, & g(\bar{p}) \leq \xi\end{cases}
$$

It is easy to check, using condition (4), that $f([\tau, \xi]) \subset[\xi, \bar{r}]$ and $g([\xi, \bar{r}]) \subset$ $[\varepsilon, \xi]$. Define the best-response function, $b$, as $b\left(s_{1}, s_{2}\right)=\left(g\left(s_{2}\right), f\left(s_{1}\right)\right)$ for $\left(s_{1}, s_{2}\right) \in[\boldsymbol{L}, \xi] \times[\xi, \bar{r}]$. Then $b$ is continuous and its range is in $[\boldsymbol{L}, \xi] \times[\xi, \overline{\boldsymbol{r}}]$. Hence Brouwer's theorem yields a fixed point for $b$. This fixed point is a pure Nash equilibrium because of condition (3) of the theorem. There is at least a pair of Nash equilibria because if one Nash equilibrium has firm 1 using $s_{1}$ and firm 2 using $s_{2}$ then there is another in which firm 2 uses $s_{1}$ and firm 1 uses $s_{2}$.

PROOF OF PROPOSITION 5: First I verify that $\Pi^{\circ}\left(s_{1}, s_{2}\right)$ is strictly quasi-concave with respect to $s_{1}$ in the region $s_{1}<s_{2}$. The critical points of $\Pi^{\circ}\left(\cdot, s_{2}\right)$ are given by the first-order condition:

$$
2 h_{1} m_{i} \frac{\partial m_{1}^{i}}{\partial s_{1}}+\left(\frac{\partial h_{1}}{\partial s_{1}}\right)\left(m_{i}\right)^{2}=0
$$

where $h_{1}=s_{1}\left(s_{2}-s_{1}\right) / s_{2}$ and $m_{1}^{0}$ was defined in (5.7). We can rewrite this as

$$
\frac{2 s_{1}\left(s_{2}-s_{1}\right)\left(1-3 \alpha s_{2}\right)}{\left(4 s_{2}-s_{1}\right)^{2}}+\frac{\left(s_{2}-2 s_{1}\right)\left(1+\alpha\left(s_{2}-s_{1}\right)\right)}{\left(4 s_{2}-s_{1}\right)}=0
$$

Note that for $s_{2}=1 / 3 \alpha, s_{1}=1 / 6 \alpha$ is the solution (the other "solution" is $\left.(1 / \alpha)+s_{2}>s_{2}\right)$ and $s_{1}>s_{2} / 2$ if and only if $s_{2}<1 / 3 \alpha$.

$$
\frac{\partial^{2} \Pi^{0}}{\partial s_{1}^{2}}=3\left(\frac{\partial h_{1}}{\partial s_{1}}\right)\left(\frac{\partial m_{1}^{0}}{\partial s_{1}}\right)+2 h_{1}\left(\frac{\partial^{2} m_{1}^{0}}{\partial s_{1}^{2}}\right)+\left(\frac{\partial^{2} h_{1}}{\partial s_{1}^{2}}\right) m_{1}
$$

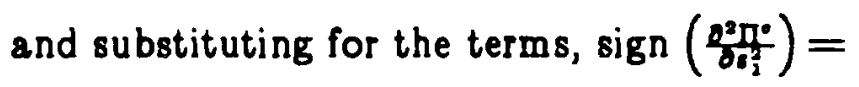

$$
\operatorname{sign}\left(\frac{3\left(s_{2}-2 s_{1}\right)\left(1-3 \alpha s_{2}\right)}{4 s_{2}-s_{1}}+\frac{2 s_{1}\left(s_{2}-s_{1}\right)\left(1-3 \alpha s_{2}\right)}{\left(4 s_{2}-s_{1}\right)^{2}}-2\left(1+\alpha\left(s_{2}-s_{1}\right)\right)\right)
$$

If $s_{2} \geq 1 / 3 \alpha$, then $s_{1} \leq s_{2} / 2$, and the sign is negative. For $s_{2}<1 / 3 \alpha$, rewrite the right-hand side after substituting for the second term from (5.9) and get

$$
\operatorname{sign}\left(\frac{3\left(s_{2}-2 s_{1}\right)\left(1-3 \alpha s_{2}\right)}{\left(4 s_{2}-s_{1}\right)}-\frac{\left(s_{2}-2 s_{1}\right)\left(1+\alpha\left(s_{2}-s_{1}\right)\right)}{\left(4 s_{2}-s_{1}\right)}-2\left(1+\alpha\left(s_{2}-s_{1}\right)\right)\right)
$$


which is negative since $s_{1}>s_{2} / 2$ at the critical points. Thus, $\Pi^{\circ}$ is strictly quasi-concave with respect to $s_{1}$ in the region $s_{1}<s_{2}$, and $g(\cdot)$ is a continuous function. To verify that $g(\cdot)$ is strictly increasing, note that

$$
g^{\prime}\left(s_{2}\right)=-\left(\frac{\partial^{2} \Pi^{\circ}\left(g\left(s_{2}\right), s_{2}\right) / \partial s_{1} \partial s_{2}}{\partial^{2} \Pi^{\circ}\left(g\left(s_{2}\right), s_{2}\right) / \partial s_{1}^{2}}\right)
$$

and since $\partial^{2} \Pi^{\circ}\left(g\left(s_{2}\right), s_{2}\right) / \partial s_{1}^{2}<0, g^{\prime}\left(s_{2}\right)>0$ if and only if $\partial^{2} \Pi^{\circ}\left(g\left(s_{2}\right), s_{2}\right) / \partial \dot{s}_{1} \partial s_{2}>$ 0 . But sign $\left(\partial^{2} \Pi^{\circ}\left(g\left(s_{2}\right), s_{2}\right) / \partial s_{1} \partial s_{2}\right)=\operatorname{sign}\left(\partial^{2} \ln \Pi^{\circ}\left(g\left(s_{2}\right), s_{2}\right) / \partial s_{1} \partial s_{2}\right)$, and

$$
\begin{aligned}
\frac{\partial^{2} \ln \Pi^{\circ}}{\partial s_{1} \partial s_{2}} & =\frac{1}{\left(s_{2}-s_{1}\right)^{2}}-\frac{8}{\left(4 s_{2}-s_{1}\right)^{2}}+\frac{2 \alpha^{2}}{\left(1+\alpha\left(s_{2}-s_{1}\right)\right)^{2}}, \\
& =\frac{8 s_{2}^{2}-7 s_{1}^{2}+8 s_{1} s_{2}}{\left(\left(s_{2}-s_{1}\right)\left(4 s_{2}-s_{1}\right)\right)^{2}}+\frac{2 \alpha^{2}}{\left(1+\alpha\left(s_{2}-s_{1}\right)\right)^{2}}>0
\end{aligned}
$$

for $s_{1}<s_{2}$.

FROOF OF PROPOSITION 6: First I verify that $\Pi^{\circ}\left(\cdot, s_{2}\right)$ is strictly quasi-concave with respect to $s_{1}$ in the region $s_{1}>s_{2}$. The critical points of $\Pi^{\circ}\left(\cdot, s_{2}\right)$ are given by:

$$
2 h_{2} m_{1}^{\circ} \frac{\partial m_{i}^{\circ}}{\partial s_{1}}+\left(\frac{\partial h_{2}}{\partial s_{1}}\right)\left(m_{1}\right)^{2}=0 .
$$

where $h_{2}=s_{1}-s_{2}$ and $m_{1}=\left(2 s_{1} /\left(4 s_{1}-s_{2}\right)\right)\left(1-\alpha\left(s_{1}+\left(s_{2} / 2\right)\right)\right.$ (cf. (5.8)). Substituting for $h_{2}, \partial h_{2} / \partial s_{1}, m_{1}^{o}$, and $\partial m_{1}^{0} / \partial s_{1}$, we get after some simplification $s_{1}\left(1-\alpha s_{1}-\frac{\alpha s_{2}}{2}\right)-\left(\frac{2\left(s_{1}-s_{2}\right)}{4 s_{1}-s_{2}}\right)\left(\alpha s_{1}\left(4 s_{1}-s_{2}\right)+s_{2}\left(1-\alpha s_{1}-\frac{\alpha s_{2}}{2}\right)\right)=0$.

and after more algebra,

$$
\left(\frac{\left(4 s_{1}-s_{2}\right) s_{1}}{2\left(s_{1}-s_{2}\right)}\right)\left(3 \alpha s_{1}-1-\frac{3}{2} \alpha s_{2}\right)+s_{2}\left(1-\alpha s_{1}-\frac{\alpha s_{2}}{2}\right)=0 .
$$

We note that $(1 / 3 \alpha)<s_{1}<(1 / 3 \alpha)+\left(s_{2} / 2\right)$ at the critical points. Now,

$$
\frac{\partial^{2} \Pi^{\circ}}{\partial s_{1}^{2}}=3 \frac{\partial m_{1}^{0}}{\partial s_{1}}+2 h_{2} \frac{\partial^{2} m_{1}^{0}}{\partial s_{1}^{2}} \text {. }
$$

Hence, $\operatorname{sign}\left(\frac{0^{2} n^{\circ}}{\partial \delta_{1}^{\circ}}\right)$

$$
\begin{aligned}
& =\operatorname{sign}\left(\frac{4 s_{2}\left(s_{1}-s_{2}\right)\left(4-3 \alpha s_{2}\right)}{\left(4 s_{1}-s_{2}\right)}-3\left(\alpha s_{1}\left(4 s_{1}-s_{2}\right)+s_{2}\left(1-\alpha s_{1}-\frac{\alpha s_{2}}{2}\right)\right)\right) \\
& =\operatorname{sign}\left(-36 \alpha s_{1}^{2}\left(s_{1}-s_{2}\right)-4 s_{1}\left(3 \alpha s_{1}^{2}-s_{2}\right)-13 s_{2}^{2}-\alpha s_{2}^{2}\left(12 s_{1}-(21 / 2) s_{2}\right)\right) \\
& >0
\end{aligned}
$$


since $3 \alpha s_{1}>1 \Rightarrow 3 \alpha s_{1}^{2}>s_{2}$. Hence, $\Pi^{\circ}$ is strictly quasi-concave with respect to $s_{1}$ in the region $s_{1}>s_{2}$, and $f(\cdot)$ is a continuous function.

To prove $f^{\prime}\left(s_{2}\right)>0$, it suffices to show that $\left(\partial^{2} \ln \Pi^{\circ} / \partial s_{1} \partial s_{2}\right)\left(f\left(s_{2}\right), s_{2}\right)>0$. And $\left(\partial^{2} \ln \Pi^{\circ} / \partial s_{1} \partial s_{2}\right)\left(f\left(s_{2}\right), s_{2}\right)$

$$
\begin{aligned}
& =\frac{1}{\left(f\left(s_{2}\right)-s_{2}\right)^{2}}-\frac{4}{\left(\frac{2}{\alpha}-2 f\left(s_{2}\right)-s_{2}\right)^{2}}-\frac{8}{\left(4 f\left(s_{2}\right)-s_{2}\right)^{2}} \\
& =\left(\frac{8}{16\left(f\left(s_{2}\right)-s_{2}\right)^{2}}-\frac{8}{\left(4 f\left(s_{2}\right)-s_{2}\right)^{2}}\right)+\left(\frac{4}{8\left(f\left(s_{2}\right)-s_{2}\right)^{2}}-\frac{4}{\left(2-2 f\left(s_{2}\right)-s_{2}\right)^{2}}\right) .
\end{aligned}
$$

Now, $16\left(f\left(s_{2}\right)-s_{2}\right)^{2}<16\left(f\left(s_{2}\right)-\left(s_{2} / 4\right)\right)^{2}=\left(4 f\left(s_{2}\right)-s_{2}\right)^{2}$ and $8\left(f\left(s_{2}\right)-\right.$ $\left.s_{2}\right)^{2}<8\left((1 / 3 \alpha)+\left(s_{2} / 2\right)-s_{2}\right)^{2}=2\left((2 / 3 \alpha)-s_{2}\right)^{2}<4\left((2 / 3 \alpha)-s_{2}\right)^{2}<$ $\left((2 / \alpha)-2 f\left(s_{2}\right)-s_{2}\right)^{2}$ using the fact that $f\left(s_{2}\right)<(1 / 3 \alpha)+\left(s_{2} / 2\right)$. Hence, $\left(\partial^{2} \ln \Pi^{\circ} / \partial s_{1} \partial s_{2}\right)\left(f\left(s_{2}\right), s_{2}\right)>0$ and we are done.

PROOF OF PROPOSITION 7: Clearly, $\Pi^{\circ}(f(0), 0)>\Pi^{\circ}(g(0), 0)=0$ and $\Pi^{\circ}(g(1 / 2 \alpha), 1 / 2 \alpha)>\Pi^{\circ}(f(1 / 2 \alpha), 1 / 2 \alpha)=0$. Also, $\left(\partial \Pi^{\circ} / \partial s\right)\left(s_{1}, s\right)>0$ for $s_{1}<s$ and $\left(\partial \Pi^{\circ} / \partial s\right)\left(s_{1}, s\right)<0$ for $s_{1}>s$, so that $\Pi^{\circ}(g(s), s)$ is strictly increasing in $s$ and $\Pi^{\circ}(f(s), s)$ is strictly decreasing in $s$. Hence there exists a $\xi \in(0,1 / 2 \alpha)$ with the stated properties.

PROOF OF PROPOSITION 8: By direct numerical computation. PROOF OF PROPOSITION 9: Apply Theorem 4. The asymmetry comes from the fact that if two firms have the same product their profits are zero.

PROOF OF PROPOSITION 10: As discussed above.1 


\section{APPENDDX 2}

\section{EXISTENCE THEOREMS FOR A NASH EQUILIRRTUM}

Let there be $n(n>1)$ firms with strategy sets $S_{i} \subset \Re^{m}, i=1, \ldots, n$. Let $S$ denote $S_{1} \times \cdots \times S_{n}$ and $S_{-i}$ denote $S_{1} \times \cdots \times S_{i-1} \times S_{i+1} \times \cdots \times S_{n}$; generic elements of $S_{i}, S_{-i}$, and $S$ are denoted by $s_{i}, s_{-i}$, and $s$, respectively. In general, $S_{i}$ could depend upon $s_{-i}$, but we shall suppress this dependence in what follows; all of the existence theorems given below continue to hold if $S_{i}$ is a. continuous correspondence of $s_{-i}$. Let $\Pi_{i}: S \rightarrow \Re$ be the payoff function of. the ith firm. Elements of $S_{i}$ are called pure strategies of $i$. A mixed strategy of $i$ is a Borel probability measure, $\mu_{i}$, on $S_{i}$. Let $P\left(S_{i}\right)$ denote the set of (Borel) probability measures on $S_{i}$; let $P(S)=P\left(S_{1}\right) \times \cdots \times P\left(S_{n}\right)$; and denote the expectation operator with respect to $\mu \in P(S)$ by $\mathcal{E}_{\mu}$. Pure and mixed Nash equilibria are defined as follows:

DEFINITION. $s^{*} \in S$ is a pure Nash equilibrium if $\Pi_{i}\left(s_{i}^{*}, s_{-i}^{*}\right) \geq \Pi_{i}\left(s_{i}, s_{-i}^{*}\right)$ for all $s_{i} \in S_{i}$.

DEFINITION. $\mu^{*} \in P(S)$ is a mixed Nash equilibrium if $\mathcal{E}_{\mu^{*}}\left(\Pi_{i}\right) \geq \mathcal{E}_{\left(\mu_{i}, \mu_{-}, j\right.}\left(\Pi_{i}\right)$ for all $\mu_{i} \in P\left(S_{i}\right)$.

(Of course, pure Nash equilibria are mixed Nash equilibria with degenerate probability measures.) The following theorems of Debreu (1952) and Glicksberg (1952) are the basic existence theorems for a pure and mixed Nash equilibrium, respectively.

THEOREM (DerReu). Let $S_{i} \subset \Re^{m}$ be nonempty, compact, and convex. If for $i=1, \ldots, n, \Pi_{i}: S \rightarrow \Re$ is continuous in $s$ and quasi-concave in $s_{i}$, then there exists a pure Nash equilibrium.

THEOREM (GLickanes). Let $S_{i} \subset \Re^{m}$ be nonempty and compact. If for $i=$ $1, \ldots, n, \Pi_{i}: S \rightarrow \Re$ is continuous in $s$, then there exists a mixed equilibrium.

These theorems are themselves applications of Kakutani's (1941) and Glicksberg's (1952) fixed-point theorems, respectively, in conjunction with Berge's (1957, Section 9, Theorem 7) theorem. (Hildenbrand (1974) is an easily available reference for these theorems.) My Theorem 4 uses Brouwer's fixed-point theorem. THEOREM (Brouwan). If $S \subset \Re^{m}$ is nonempty, compact, and convex, and $f: S \rightarrow$ $S$ is a continuous function, then $f$ has a fixed point. 


\section{REFERENCES}

Berge, C. ( 1957), "Théorie Générale des Jeux àn Personnes," Memorials des Sciences Mathématiques, Fasc. 138.

Bertrand, J. (1883), "Review of Théorie Mathématique de la Richesse Sociale and Recherches sur les Principes Mathématiques de lo Théorie des Richesses," Journal des Savants, 499-508.

Bresnahan, T. ( 1981), "A Model of Product Differentiation with Advance Investment in Product Quality,"mimeo, Department of Economics, Stanford University.

Chamberlin, E.H. ( 1933), The Theory of Monopolistic Competition, Cambridge. Harvard University Press.

d'Aspremont, C., J. Gabszewicz, and J. Thisse ( 1979), "On Hotelling's "Stability in Competition","Econometrica, 47, 1145-50.

Dasgupta, P. and E. Maskin ( 1982a), "The Existence of Equilibrium in Discontinuous Economic Games, 1: Theory,"Research Paper No. 82/54, London School of Economics.

( $1982 \mathrm{~b})$, "The Existence of Equilibrium in Discontinuous Economic Games, 2: Applications,"Research Paper No. 82/55, London School of Economics.

Debreu, G. ( 1952), "A Social Equilibrium Existence Theorem," Proceedings of The National Academy of Sciences, 38, 886-93.

Downs, A. ( 1957), An Economic Theory of Democracy, New York. Harper and Row.

Dunford and Schwartz ( 1957), Linear Operators, Vol. 1, New York. Wiley Interscience.

Eaton, B. and R. Lipsey ( 1975), "The Principle of Minimum Differentiation Reconsidered: Some New Developments in the Theory of Spatial Competition," Review of Economic Studies, 42, 27-50.

Economides, N. ( 1980 ), Oligopoly in Markets for Products Differentiated by their Characteristics, Ph.D thesis, University of California, Berkeley.

Friedman, J. ( 1977), Oligopoly and the Theory of Games, New York. North-Holland.

Gabszewicz, J. and J. Thisse ( 1979), "Price Competition, Quality, and Income Disparities," Journal of Economic Theory, 20, 340-59. 
Industry," Journal of Economic Theory, 22, 327-38.

Glicksberg, I. L. ( 1952), "A Further Generalization of the Kakutani Fixed Point Theorem with Application to Nash Equilibrium Points," Proceedings of the National Academy of Sciences, 38, 170-4.

Hauser, J. and S. Shugan ( 1983), "Defensive Marketing Strategy,"Working Paper, University of Chicago, Chicago.

Hay, D. ( 1976), "Sequential Entry and Entry-Deterring Strategies," Oxford. Economic Papers, 240-57.

Hildenbrand, W. (1974), Core and Equilibria of a Large Economy, Princeton.

Princeton University Press.

Hotelling, H. ( 1929), "Stability in Competition," Economic Journal, 41-57. Kakutani, S. ( 1941), "A Generalization of Brouwer's Fixed Point Theorem," Duke Mathematical Journal, 8, 457-9.

Lane, W. ( 1980), "Product Differentiation in a Market with Endogenous Sequential Entry," Bell Journal of Economics, 22, 237-60.

Moorthy, K.S. ( 1983), "Market Segmentation, Self-selection, and Product Line Design," Working Paper No. MERC 82-01, Graduate School of Management, University of Rochester.

Nishimura, K. and J. Friedman ( 1981), "Existence of Nash Equilibrium in $n$ Person Games without Quasi-concavity,"International Economic Review, 22, 637-48.

Novshek, W. ( 1980), "Equilibrium in Simple Spatial (or Differentiated Product)

Models," Journal of Economic Theory, 22, 313-26.

Porter, M. ( 1980), Competitive Strategy, New York. The Free Press.

Prescott, E. and M. Visscher ( 1977), "Sequential Location Among Firms with Foresight," Bell Journal of Economics, 8, 378-93.

Roberts, D.J. and H. Sonnenschein ( 1976), "On the Existence of Cournot Equilibrium without Conceve Profit Functions," Journal of Economic Theory, $13,112-7$. (1977), "On the Foundations of the Theory of Monopolistic Competition," Econometrica, 45, 101-14.

Salop, S. ( 1979), "Strategic Entry Deterrence," American Economic Review, $69,335-8$. 
Schmalansee, S. ( 1978), "Entry-deterrence in the Ready-to-eat Breakfast Cereal Industry," Bell Journal of Economics, 9, 305-27.

Selten, R. (1975), "Re-examination of the Perfectness Concept for Equilibrium Points in Extensive Games," International Journal of Game Theory, 4, 25-55.

Shaked, A. and J. Sutton ( 1982), "Relaxing Price Competition through Product Differentiation," Review of Economic Studies, 40, 3-13.

Smithies, A. (1941), "Optimum Location in Spatial Competition," Journal. of Political Economy, 49, 423-39.

Steiner, P.O. (1961), "Monopoly and Competition in Television: Some Policy Issues," The Manchester School of Economic and Social Studies, 29, 10731.

Stokey, N. ( 1980), "Job Differentiation and Wages," Quarterly Journal of Economics, 431-49. 